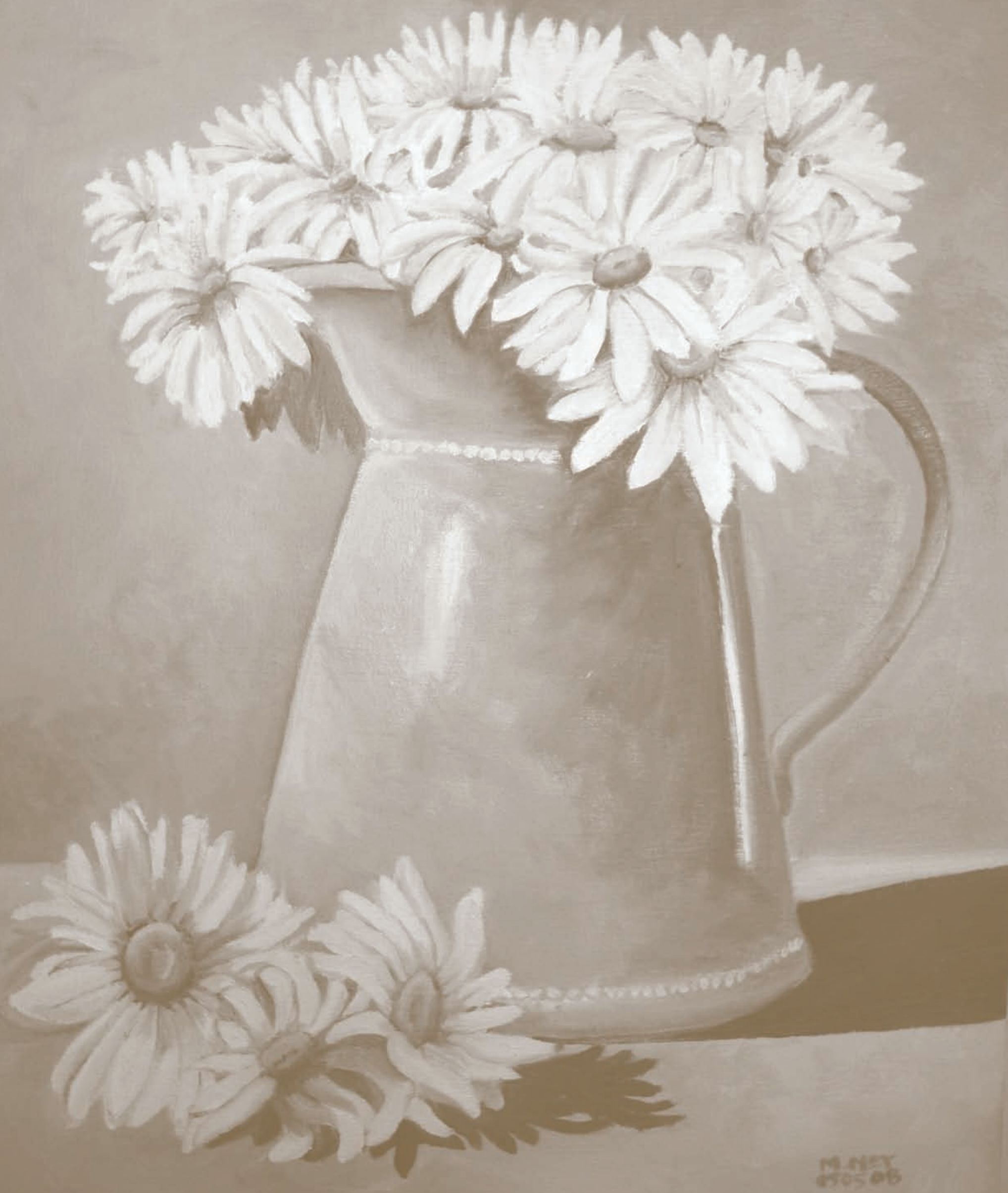




\section{4 factores sociodemográficos asociados con el embarazo en la adolescencia, en los departamentos de Copán, Lempira y Ocotepeque, para el año 2001}

María. Victoria Ponce Mendoza

\section{JUSTIFICACIÓN}

El embarazo en la adolescencia expresado demográficamente como tasa de fecundidad adolescente, es en la actualidad un motivo de preocupación mundial, regional y nacional debido a que, supone un alto riesgo psicológico y de salud para la madre y su hijo comprometiendo su futuro socioeconómico y el desarrollo nacional (OPS, 1995).

Pese a esa reconocida preocupación por responder a las crecientes necesidades de la salud reproductiva de los y las adolescentes, según Guzmán (2001), en América Latina existen insuficiencias en la capacidad de los países para poner en práctica programas efectivos, lo cual obedece entre otras razones, a la escasez de información y análisis que identifiquen de forma precisa el contexto social, cultural, económico y demográfico en el que se desenvuelve la salud reproductiva.

Según la ENESF/2001, en Honduras la tasa específica de fecundidad para mujeres entre 15-19 años para el año 2000 fue de 137 por mil y la tasa global de fecundidad fue de 4.4 hijos por mujer, de las más altas en América Latina; asimismo, "en el año 2000 la tasa de crecimiento de la población, se estimó en 2.8 por mil habitantes, una de las más altas en el contexto de Latinoamérica. Con una proyección poblacional para el 2050 de trece millones novecientos veinte mil habitantes" (Banguero, 2000).

Se analizan entonces, los factores sociodemográficos asociados con el embarazo en la adolescencia, desde el enfoque de Salud Sexual y Reproductiva, tomando en cuenta, como población base, las mujeres adolescentes con una edad comprendida entre los 12 y los 19 años, edad más frecuente del inicio de la actividad sexual. El área geográfica incluye a los departamentos de Copán, Lempira, y Ocotepeque, por ser estos los que, según el Informe de Desarrollo Humano 2003, tienen el índice de Desarrollo Humano más bajo en todo el país.

\section{PERSPECTIVA TEÓRICA}

Embarazo en la adolescencia: Se define como aquella gestación que ocurre durante los dos primeros años ginecológicos de la mujer (edad ginecológica $0=$ edad de la menarquía), inicio del período menstrual y de la capacidad reproductiva) y/o cuando la adolescente mantiene la total dependencia social y económica de la familia parental. También ha sido llamado el síndrome del fracaso, o la puerta de entrada al ciclo de la pobreza. (OPS, 1992) Sin embargo, la fecundidad de las adolescentes también puede entenderse a la inversa, al sostenerse que sería la pobreza la que conduciría a la existencia de embarazos en edades tempranas (Chackiel, 2004).

El embarazo adolescente conlleva riesgos biológicos como: las complicaciones obstétricas; deficiente atención médica durante el embarazo, toxemias del embarazo y del parto prematuro; anemia; desproporción cefalopelvica; distocias mecánicas y dinámicas; parto prolongado y difícil; muerte; abortos provocados y sus complicacio- 
nes; perforaciones uterinas; hemorragias; infecciones; aumento de la morbimortalidad infantil; prematurez; bajo peso al nacer y enfermedades congénitas (Ascanio, sin fecha).

Es por lo anterior que la Salud Reproductiva, plantea el derecho de las jóvenes a obtener información y entraña la capacidad de disfrutar de una vida sexual satisfactoria; sin riesgos; de procrear; la libertad de decidir (hacerlo o no hacerlo), cuando y con qué frecuencia; la libre elección de métodos de planificación de la familia, así como otros métodos seguros, eficaces, asequibles y aceptables para la regulación de la fecundidad; el derecho a recibir servicios adecuados de atención de la salud que permitan los embarazos y los partos sin riesgos y den a las parejas las máximas posibilidades de tener hijos sanos y así como el derecho a la igualdad de género (UNFPA, 1994).

\section{CONTEXTO}

El Estado de la Población de Honduras UNFPA, 2004, reportó que el crecimiento demográfico ha bajado de $3.0 \%$ en la década de los ochenta a $2.8 \%$ a finales de los noventa, así como la tasa de fecundidad, de 4.9 hijos en 1990-95 a 3.7 hijos por mujer en el año 2003, pero sigue siendo una de las cinco más altas de América Latina. Asimismo, la tasa específica de fecundidad para mujeres entre 15 y 19 años para el 2000 fue de 137 por mil (ENESF, 2001).

Es evidente que la fecundidad en Honduras ha venido bajando, sin embargo, la disminución de las tasas se debe a las mujeres adultas, mientras tanto, la fecundidad adolescente no muestra avances; a nivel nacional, casi el 60\% de las mujeres de entre 15-24 años ha tenido relaciones sexuales, solo el $9 \%$ han usado algún anticonceptivo en la primera relación sexual, pero esta proporción se reduce a casi la mitad en el caso de las mujeres del área rural y las de menos años de educación, además, el método utilizado, en casi la mitad de los casos es el ritmo y el retiro, los cuales tienen mayor tasa de falla y en consecuencia, contribuyen a que una proporción de mujeres adolescentes se embaracen (cifras Honduras, 2004).
Los Registros Administrativos de los dos hospitales más importantes del país, Hospital Materno Infantil y Hospital San Felipe para el año 2005, demuestran que los egresos de parto de adolescentes presentan cifras similares desde el año 2002 al 2005, lo cual da testimonio de que los programas actuales con respecto a la salud reproductiva orientados para las adolescentes aún no brindan resultados adecuados que contribuyan a la disminución del problema del embarazo temprano.

En los departamentos de Copán, Lempira y Ocotepeque, la situación de salud según la ENESF/2001, indica que la experiencia sexual de las jóvenes de entre 15-24 años, es mayor que a nivel nacional; casi el 58\% de las mujeres manifestó haber tenido experiencia sexual y de ellas, el 20\% tuvo su primera relación antes de cumplir los 15 años, el 69\% antes de los 18 años y sólo el 6\% utilizó algún anticonceptivo durante la primera relación sexual (Population Refernce Bureau, 2004).

Aunque ha habido un aumento en el uso de métodos de planificación familiar, el porcentaje de uso en los tres departamentos, es el más bajo de todo el país; el 53\% de las mujeres no utiliza métodos anticonceptivos, sólo el 47\% lo hace, de las cuales el $31 \%$ usa métodos modernos (pastillas, dispositivo intrauterino, esterilización, etc.) y el 16\% utiliza los tradicionales (los naturales, retiro, ritmo y el Billings). Asimismo, la tasa global de fecundidad es la segunda más elevada a nivel nacional (Population Refernce Bureau, 2004) (Tabla No. 1).

Aunado a los problemas de fecundidad, los departamentos de Copán, Lempira y Ocotepeque, se caracterizan por la pobreza rural generalizada, con el paso de

\section{Tabla No. 1. Situación de la fecundidad de la población de los departamentos de Copán, Lempira y Ocotepeque, 2001}

\begin{tabular}{|l|c|c|}
\hline \multicolumn{1}{|c|}{ Datos de fecundidad } & Nacional & Regional \\
\hline TGF, 98-00, ENESF/01 & $\begin{array}{c}4.4 \text { hijos por } \\
\text { mujer }\end{array}$ & $\begin{array}{c}5.7 \text { hijos por } \\
\text { mujer }\end{array}$ \\
\hline Tasa específica $15-19$ años & 137 por mil & 116 por mil \\
\hline Uso de anticonceptivos & $61.8 \%$ & $47.2 \%$ \\
\hline
\end{tabular}

Fuente: Population Reference Bureau, Washington, DC, EE.UU, marzo 2004 
los años, la situación de pobreza se ha agudizado con tendencia a la profundización, debido principalmente, a que los programas implementados por el Estado desde la década de los años 50 han logrado poco impacto, no se cuenta con una propuesta de desarrollo sustentable, en consecuencia, la región occidental presenta los niveles de carencia más elevados en todo el país y con el mayor rezago, aislamiento y pobreza, por tanto, se convierte en una zona expulsora de su población (Honduras, SEDP, PNUD, PLATS/UNAH, 2005).

\section{SITUACIÓN SOCIODEMOGRÁFICA DE LA POBLA- CIÓN ADOLESCENTE}

Población femenina adolescente: En la región occidental que ocupan los departamentos de Copán, Lempira y Ocotepeque, la población femenina adolescente para el 2001 fue de 58,021 jóvenes que representan el 19\% del total femenino regional. Copán es el que tiene la mayoría de población femenina adolescente con un 45.14\% y Ocotepeque es que tiene menor población femenina adolescente con un $16.48 \%$ (Tabla No. 2)

Población indígena: Los pueblos indígenas, son los descendientes de las poblaciones que habitaban el país antes de la época de la conquista o la colonización o del establecimiento de las actuales fronteras estatales y que,

\section{Tabla No. 2. Población femenina absoluta y relativa de los deptos de Copán, Lempira y Ocotepeque, en relación al departamento y región, 2001}

\begin{tabular}{|c|c|c|c|c|}
\hline Departamentos & Copán & Lempira & $\begin{array}{l}\text { Ocote- } \\
\text { peque }\end{array}$ & Total \\
\hline & \multicolumn{4}{|c|}{ Población femenina } \\
\hline Femenino total & 137,074 & 119,693 & 51,048 & 307,815 \\
\hline Adolescentes & 26,188 & 22,271 & 9,562 & 58,021 \\
\hline Valores relativos & \multicolumn{4}{|c|}{$\%$} \\
\hline $\begin{array}{l}\text { Femenina en relación al } \\
\text { total regional }\end{array}$ & 44.53 & 38.88 & 16.58 & 100 \\
\hline $\begin{array}{l}\text { Fem. adol en relación al } \\
\text { total regional }\end{array}$ & 45.14 & 38.38 & 16.48 & 100 \\
\hline $\begin{array}{l}\text { Fem. adol en relación al } \\
\text { total por Depto }\end{array}$ & 19.11 & 18.61 & 18.73 & 18.85 \\
\hline
\end{tabular}

Fuente: Elaboración propia, basados en datos censales, INE, 2001. cualquiera que sea su situación jurídica, conservan todas sus propias instituciones sociales, económicas, culturales y políticas, o parte de ellas.

En la región occidental, se encuentra ubicado el $34 \%$ de la población indígena nacional, predominando el pueblo Lenca con un $26.5 \%$ del total nacional y el 78 $\%$ de la población indígena regional; el segundo pueblo en importancia es el chortí con el $7 \%$ del total nacional y el $20.6 \%$ del total indígena regional; la presencia de otros pueblos indígenas en la zona es mínima, abarcando únicamente el $0.5 \%$ del total indígena nacional y el $1.4 \%$ de la población indígena regional

Población indígena femenina adolescente: La población indígena femenina adolescente en los tres departamentos constituye el $23.56 \%$ con respecto a la población femenina adolescente total de la región, el departamento de Lempira es el que cuenta con la mayoría de la población indígena femenina adolescente, con un $16.81 \%$ el porcentaje en los otros departamentos es menor, en Copán constituye sólo el 2.49\% (gráfico No. 1).

Estado conyugal según hija/o nacido vivo: El $11.17 \%$ de las adolescentes independientemente del estado conyugal tiene alguna hija o hijo nacido vivo; lo anterior, muestra la ineficiente y/o inexistente orientación y educación sexual a las jóvenes llevándolas a asumir roles de adultas, muchas de ellas sin el apoyo de su pareja o su

\section{Gráfico No. 1. Porcentaje de población femenina adolescente, según pueblos Indígenas en Copán, Lempira y Ocotepeque, 2001}

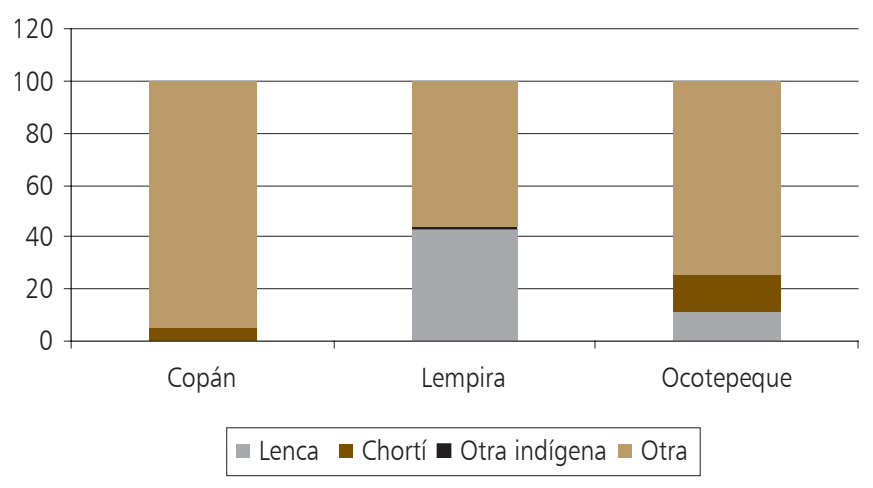

Fuente: Elaboración propia, basados en datos censales, INE, 2001. 
familia, en ese sentido, se deben de tomar oportunamente las medidas que garanticen el respeto a los derechos de las jóvenes sobre todo a la educación integral y a la salud sexual y reproductiva.

En relación al total de hijas/os nacidos vivos, el 20.45\% lo aporta las adolescentes en estado civil soltera, junto con el $4.40 \%$ de las jóvenes separadas, divorciadas $\mathrm{y}$ viudas hacen en total un $24.85 \%$ porcentaje bastante elevado por tratarse de jóvenes sin la madurez psíquica, física y emocional, peor aún, si no reciben apoyo económico por parte del padre de sus progenitores o de su familia, viven en un condiciones de pobreza y precariedad (gráfico No. 2). se presenta la misma tendencia en los tres depar-

Gráfico No. 2. Estado conyugal de adolescentes en porcentaje según el total de hija/o nacido vivo, en la región Occidental de Honduras, 2001

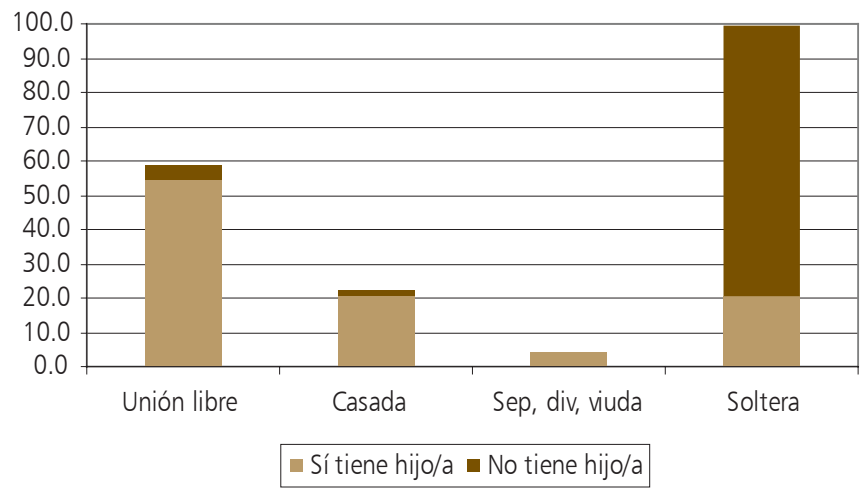

Fuente: Elaboración propia, con base a datos Redatam, INE, 2001

Gráfico No. 3. Estado conyugal de adolescentes en porcentaje según el total de hijas e hijos nacidos vivos, en los deptos de Copán, Lempira y Ocotepeque, en relación al total regional, 2001

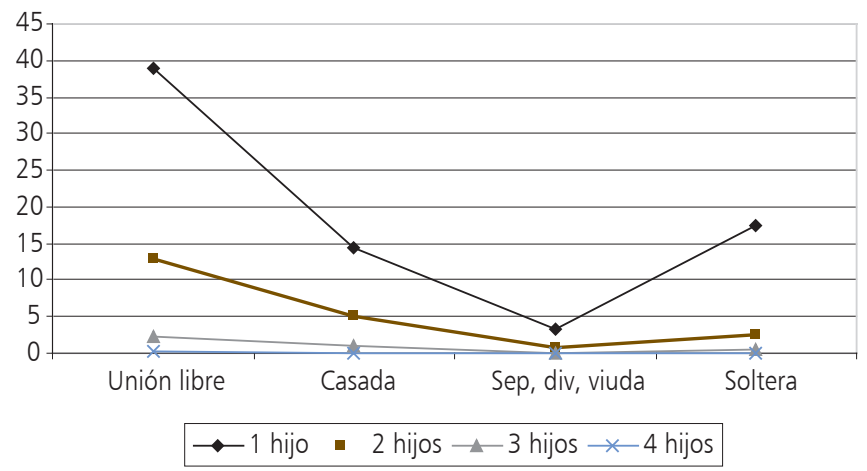

Fuente: Elaboración propia, con base a datos Redatam, INE, 2001 tamentos, el promedio de hijas o hijos de las adolescentes, se incrementa independientemente del estado conyugal al que pertenezcan, lo cual define un patrón muy fuerte para el fenómeno lo que hace necesario tomar medidas pertinentes de forma inmediata (gráfico No. 3)

Estado conyugal por área de residencia urbana y rural: El estado conyugal predominante en las adolescentes con hijas/os nacidos vivos en ambas áreas de residencia, es el unión libre; las casadas del área rural superan levemente a las del área urbana; un fenómeno interesante es que hay mayor proporción de madres solteras en el área urbana que en la rural, representan un 27.8 y $19.2 \%$ respectivamente, lo cual demuestra que la paternidad irresponsable se profundiza en el área urbana; asimismo, el porcentaje de las adolescentes separadas, divorciadas y viudas es superior en el área urbana representa un $6 \%$ y sólo $4 \%$ en el área rural, indicando que la desintegración familiar es mayor en el área urbana que la rural (gráfico No. 4).

Cabe destacar que en la zona occidental, el fenómeno del embarazo en adolescentes se manifiesta mayoritariamente en área rural, representa un promedio de $85.18 \%$ en relación al total regional de adolescentes con hijas/os nacidos vivos; en cambio el promedio para el área urbana es muy inferior con un $14.82 \%$; el estado conyugal predominante es el de unión libre, representa un $54 \%$ en

\section{Gráfico No. 4. Estado conyugal} de adolescentes en porcentajes según hija/o nacido vivo, en relación al total por área de residencia, en la zona occidental de Honduras, 2001

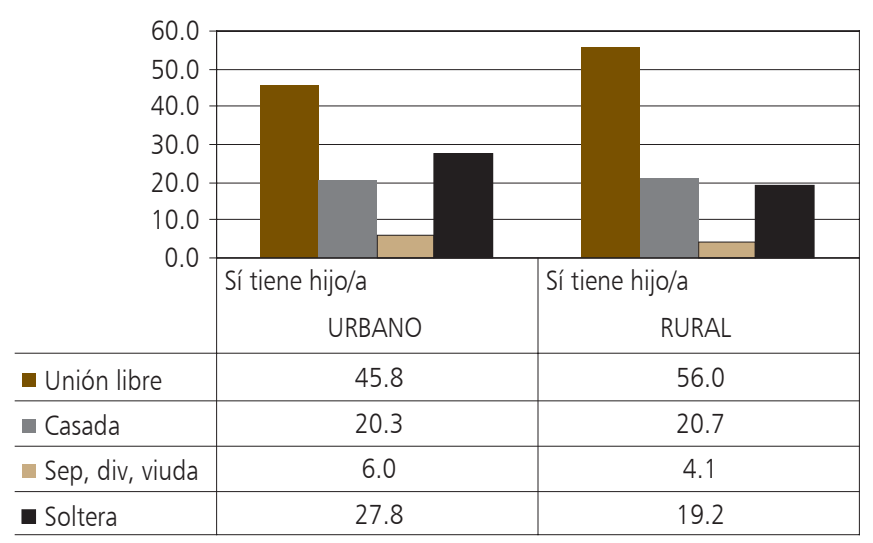

Fuente: Elaboración propia, con base a datos Redatam, INE, 2001 
la región, distribuido en un 47.7 y $6.8 \%$ en el área rural y urbana respectivamente; las jóvenes casadas con hijos/as y las madres solteras viven en su mayoría en el área rural debido a que, la zona occidental del país por lo general es bastante rural (gráfico No. 5).

En relación al total de hijas/os nacidos vivos, las jóvenes que tienen mayor proporción de hijas/os, son las que viven en unión libre en ambas áreas de residencia, presentando los promedios más altos las jóvenes del área rural. Las jóvenes en unión libre son las que más incrementan su número de hijos/as, sobre todo las que viven en el área rural, posiblemente porque en esta área la cobertura y calidad del servicio de educación pública

\section{Gráfico No. 5. Porcentaje del estado conyugal de adolescentes según hija/o nacido vivo y área de residencia, en relación al total regional de la Zona Occidental de Honduras, 2001}

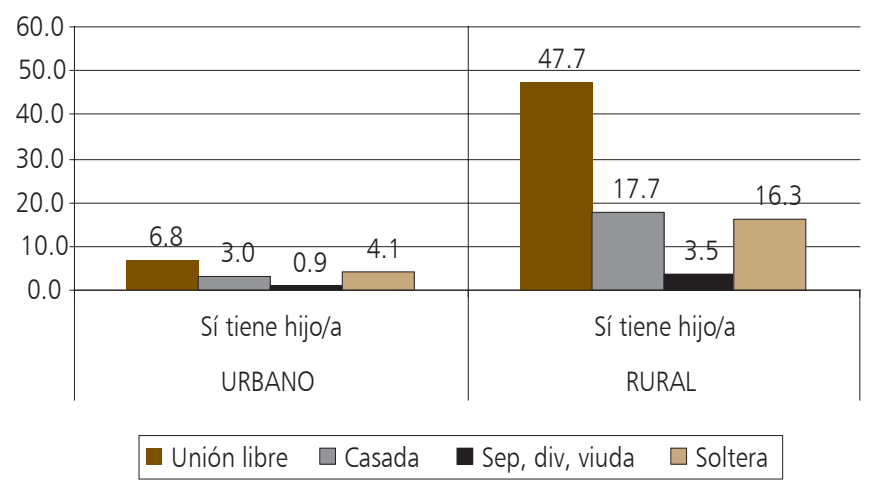

Fuente: Elaboración propia, con base a datos Redatam, INE, 2001

Gráfico No. 6. Estado conyugal de adolescentes en porcentaje según el total de hijas/ os nacidos vivos y área de residencia, en relación al total regional, de la Región Occidental, 2001

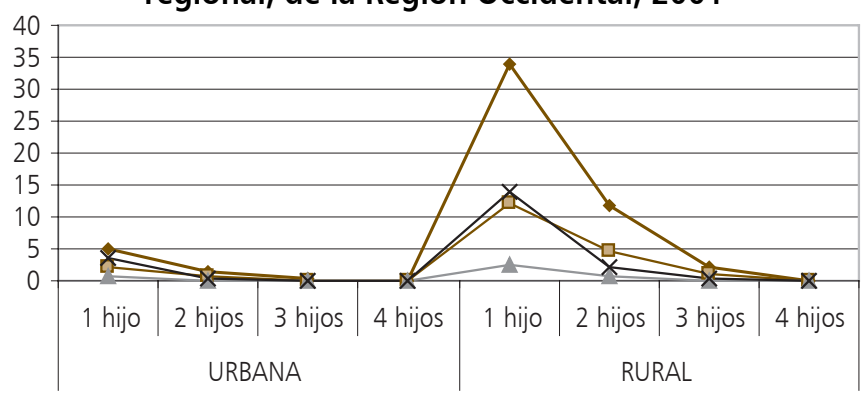

- Unión libre $\longrightarrow$ - Casada $\longrightarrow$ Sep, div, viuda $\rightarrow$ Soltera

Fuente: Elaboración propia, con base a datos Redatam, INE, 2001 es deficiente, impidiendo que las jóvenes desarrollen sus capacidades para ampliar sus opciones de vida, siendo así, se profundiza su situación de pobreza, dando como resultado bajos niveles de Desarrollo Humano en la región (gráfico No. 6).

Estado conyugal de la población indígena por área de residencia: Al comparar los valores del estado conyugal de las adolescentes de los pueblos indígenas con el total de las adolescentes en la región, se puede apreciar la similitud en el comportamiento de las jóvenes; la mayoría de ellas se encuentran solteras, pero el segundo lugar lo ocupa el estado conyugal en unión libre sobre todo en el área rural, las jóvenes de los pueblos indígenas superan solo en $1.55 \%$ a las demás jóvenes de la región (gráfico No. 7).

La mayoría de las jóvenes que tienen hijas/os nacidos vivos, viven en el área rural, solo el $0.63 \%$ vive en el área urbana, predominando en ambas áreas el estado conyugal en unión libre. En general, 88. 76 \% de las adolescentes lenca no tiene hijas/os nacidos vivos, pero el $11.24 \%$ de las jóvenes si los tiene (gráfico No. 8).

Adolescentes con alguna hija o hijo nacido vivo: Según el Censo de Población y Vivienda 2001, el 11 \% con relación al total de jóvenes de la región occidental tenían al menos un/a hija/o nacido vivo, ese porcentaje esta repartido en los tres departamentos, siendo Copán el que tiene el mayor valor con un 5.21\%; le sigue Lempira

Gráfico No. 7. Estado conyugal de adolescentes, en porcentaje según grupo poblacional, en relación al total de la zona occidental de Honduras, 2001

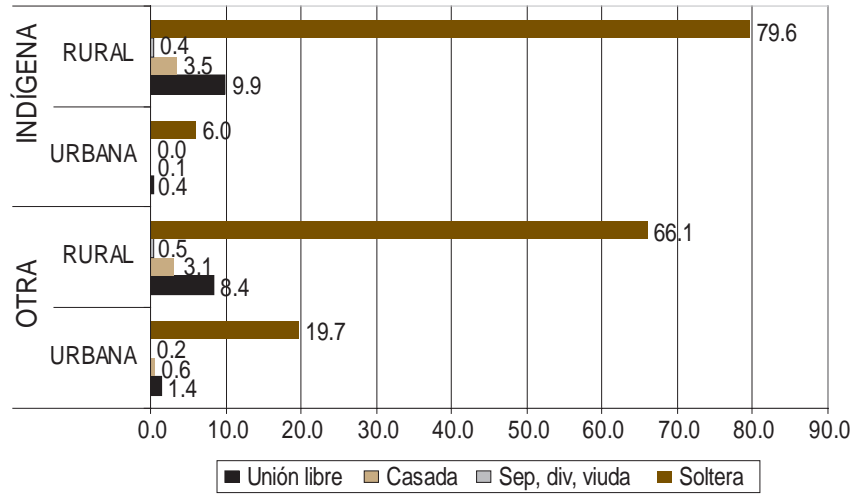

Fuente: Elaboración propia, con base a datos Redatam, INE, 2001 
Gráfico No. 8. Estado conyugal de adolescentes lenca en porcentaje, según hija/o nacido vivo y área de residencia, en los departamentos de Lempira y Ocotepeque, 2001

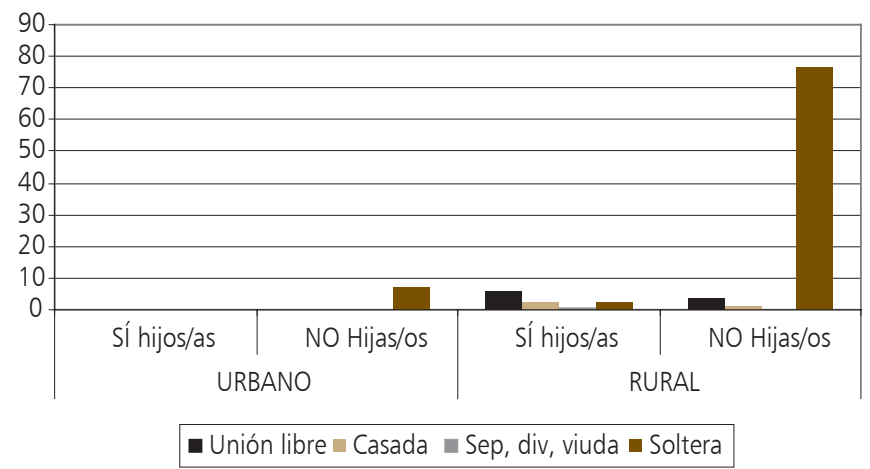

Fuente: Elaboración propia, con base a datos Redatam, INE, 2001

\section{Grafico No. 9. Indice de Desarrollo Humano de Honduras} por departamento, 2002, 2004

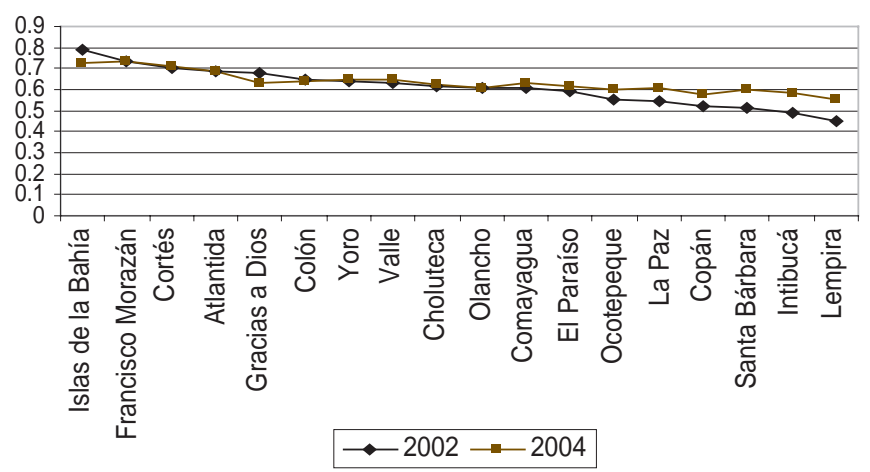

Fuente: Elaboración propia, con base a los Informes sobre Desarrollo Humano Honduras, 2002 y 2006

Gráfico No. 10. Adolescentes por edad simple en porcentaje, según hija/o nacido vivo, en los deptos de Copán,

Lempira y Ocotepeque, en relación al total regional, 2001

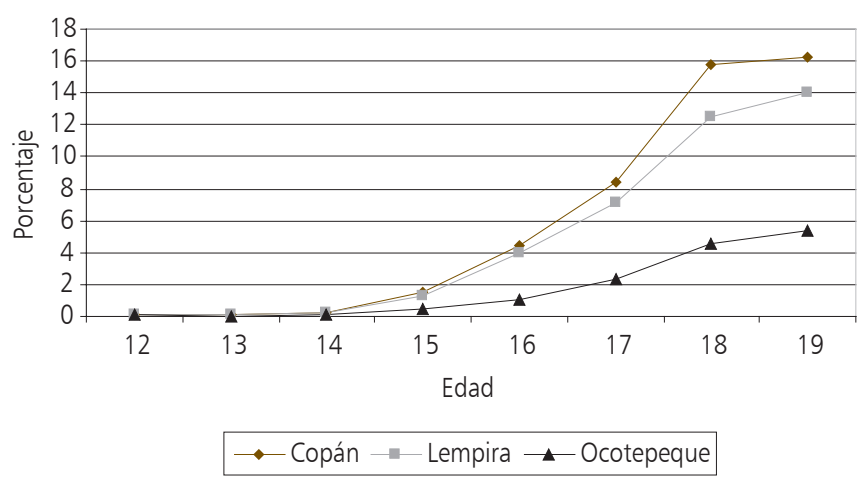

Fuente: Elaboración propia, con base a datos Redatam, INE, 2001 con el 4.39\% y finalmente Ocotepeque sólo con el 1.57\% debido a que es el departamento con menor población, representa el $16.48 \%$ en relación al total regional.

Lempira, a pesar de que tiene menor número de población adolescente, el promedio de jóvenes con algún/a hija/o se acerca al de Copán lo cual indica que el problema es más severo en este departamento. Según el Informe sobre Desarrollo Humano Honduras 2002 y 2006, Lempira, también es el departamento que presenta el Índice de Desarrollo Humano más bajo del país; Ocotepeque en cambio, presenta un mejor panorama en cuanto al menor número de adolescentes con hijas/os y los valores más altos en desarrollo humano en la región (gráfico No. 9).

El incremento en los nacimientos de acuerdo a la edad, presenta una tendencia similar en los tres departamentos, conforme aumenta la edad, también aumentan las probabilidades de tener alguna hija o hijo nacido vivo, contribuyendo así al crecimiento poblacional de sus departamentos, debido a que, entre más temprano se inicia la procreación mayores son las posibilidades de incrementar el número de hijos e hijas (gráfico No. 10).

Para mediados del 2005, la tasa de crecimiento poblacional en los departamentos de Copán y Lempira fue de $11 \%$ y en Ocotepeque fue del 10\% un punto abajo de los anteriores departamentos. En comparación con la tasa de crecimiento de la población a nivel nacional que fue del 10\%, podemos notar que Ocotepeque sigue el ritmo de crecimiento nacional, pero el ritmo de crecimiento de la población de Copán y Lempira es superior, esta por encima de la tasa nacional (gráfico No. 11).

Adolescentes de los pueblos indígenas con alguna hija o hijo nacido vivo: Las jóvenes de los pueblos indígenas, presentan una tendencia similar al resto de las jóvenes de la región, aún en el departamento de Lempira que posee la mayoría de la población indígena; en cambio, el departamento de Copán alberga menor población indígena pero es el que tiene el mayor número de casos de embarazo adolescente en la región; la tendencia de las adolescentes lenca y chortí con respecto a las/os hijas/os nacidos vivos, es similar entre los pueblos indíge- 
nas Lenca y Chortí y el resto de la población adolescente de la región (gráfico No. 12).

En comparación con el total regional de adolescentes con hija/o nacido vivo, se puede observar (gráfico No. 13) que el fenómeno del embarazo en la adolescencia en la región occidental de Honduras se manifiesta en un 2.62\% en las jóvenes indígenas, la mayoría de los casos un 8.54\% se presenta en las demás jóvenes de la zona. Esto indica contrariamente a lo que se piensa, que las manifestaciones culturales si bien influyen en el fenómeno del embarazo precoz, no son las únicas determinantes.

Adolescentes según los/as hijas/os nacidos vivos en total: En toda la región el 74\% de las jóvenes con hijas o hijos nacidos vivos, tienen una hija o hijo en promedio, el valor más alto lo presentan las jóvenes de 18 años con un $24.4 \%$, las niñas entre 12 y 14 años presentan valores más bajos, sin embargo, son alarmantes por las complicaciones que conlleva el embarazo a esa edad, tanto en la salud como en los impactos psico-sociales y económicos ya que deben asumir roles de adultas sin estar preparadas ni física, psíquica ni emocionalmente.

Las jóvenes que tienen dos hijas o hijos en promedio, representan el $21.4 \%$ en toda la región, los valores más altos los representan las jóvenes de 19 años, más inconcebible es que niñas de 15 y 16 años tengan dos hijas o hijos en promedio; peor aún, el 0.40 de las jóvenes de 17 años de edad, tiene tres hijas o hijos en promedio. El 0.48\% de las jóvenes de 19 años tiene cuatro hijas o hijos en promedio (tabla No. 3 y gráfico No. 14).

En general, a partir de los 12 años en la medida que aumenta la edad, se incrementa el porcentaje de jóvenes con embarazo precoz, igualmente, de los 15 años en adelante se incrementa el promedio de hijas o hijos. Esto demuestra que existe una clara violación a los Derechos Reproductivos de las adolescentes, lo cual implica la negación a obtener información para que las jóvenes disfruten de una vida sexual satisfactoria, sin riesgos ni presiones de procrear sobre todo a temprana edad y bajo cortos períodos intergenésicos.

De allí, que los Derechos Humanos de las jóvenes pasan desapercibidos, se cierran sus opciones en educa-
Gráfico No. 11. Pirámide de la población totalen porcentajes de la Región Occidental de Honduras, 2001

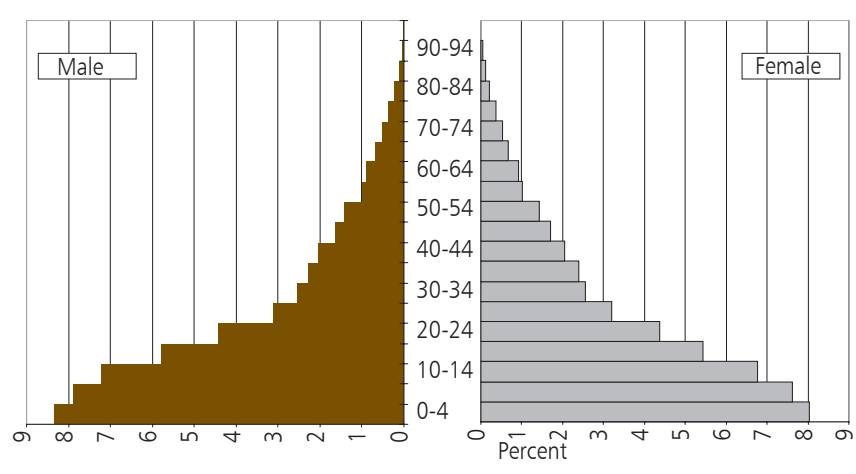

Fuente: Elaboración propia, con base a datos Redatam, INE, 2001
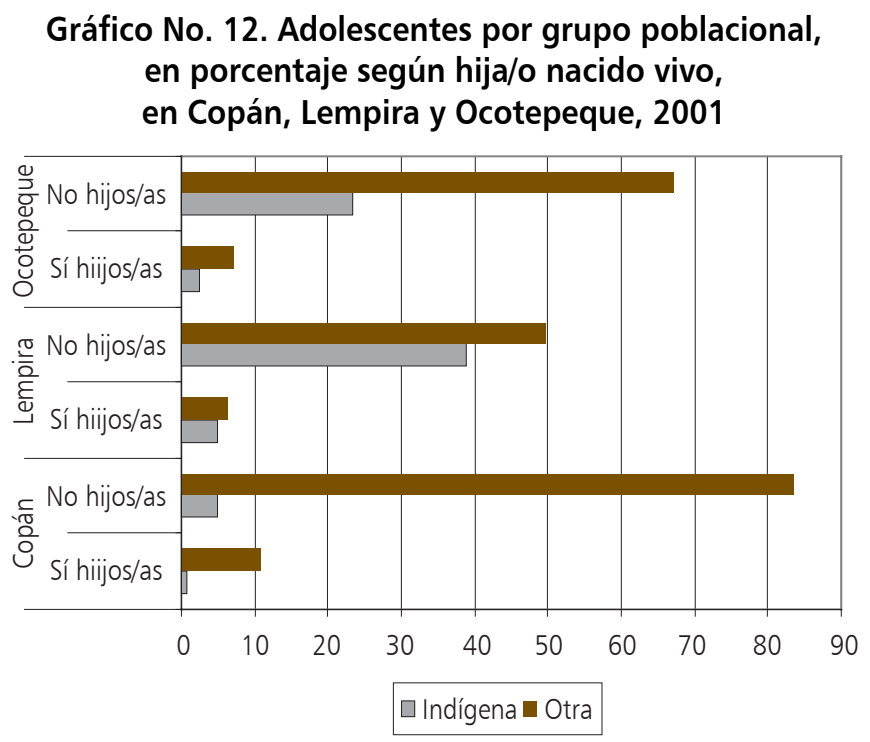

Fuente: Elaboración propia, con base a datos Redatam, INE, 2001

Gráfico No. 13. Adolescentes del occidente de Honduras, en porcentaje según grupo poblacional e hija/o nacido vivo, en relación al total regiónal, 2001

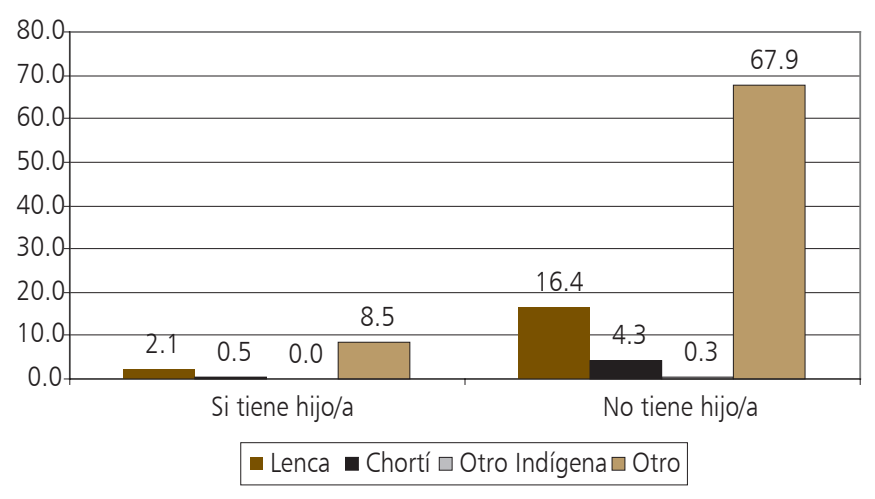

Fuente: Elaboración propia, con base a datos Redatam, INE, 2001 
ción y capacitación profesional, partos con alto riesgo, menores posibilidades de insertarse al mercado laboral, en consecuencia, enormes impactos negativos para su desarrollo personal, familiar, social y mayor atraso para el desarrollo nacional.

Particularmente en la región occidental de Honduras, el embarazo en las adolescentes constituye un serio problema, debido a las condiciones de pobreza que se presentan en la zona, según el Informe sobre Desarrollo Humano Honduras 2002, esta región es la más pobre del país, con deficiencias en los servicios públicos de salud,

Gráfico No. 14. Adolescentes, por edad simple, en porcentaje según el total de hijas/os nacidos vivos, en los deptos de Copán, Lempira y Ocotepeque, en relación al total regional, 2001

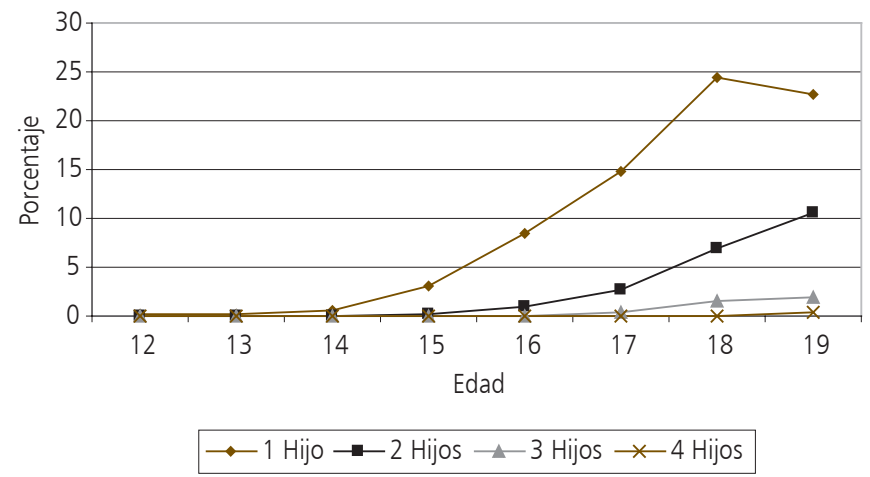

Fuente: Elaboración propia, con base a datos Redatam, INE, 2001 educación; así como las escasas fuentes de empleo para la generación de ingresos dignos.

En los departamentos de Copán, Lempira y Ocotepeque, la experiencia sexual de las jóvenes de entre 15 y 24 años es mayor que a nivel nacional, el 58\% de las mujeres manifestó haber tenido experiencia sexual, de ellas, el 20\% tuvo su primera relación antes de cumplir los 15 años; el 69\% antes de los 18 años y solo el 6\% utilizó algún anticonceptivo durante la primera relación sexual (ENESF, 2001); esto demuestra que en la zona, los programas existentes sobre salud sexual y reproductiva dirigidos a la población adolescente son insuficientes y/o inexistentes.

Adolescentes de los pueblos indígenas según los/as hijas/os nacidos vivos en total: La tendencia de las variables de fecundidad en las jóvenes indígenas es similar al resto de las adolescentes de la región, la mayoría de ellas tiene un hijo/a en promedio, pero al incrementarse su edad, también se eleva el número de hijas/os nacidos vivos, el 73\% de las que tiene hijos/as, tiene un/a hijo/a en promedio; el 23\% tiene dos hijos/as en promedio; el $3.5 \%$ tiene tres hijos/as en promedio y apenas el $0.5 \%$ tiene cuatro hijos/as.

Situación educativa: En toda la zona occidental, el 66\% de las jóvenes no estudia actualmente, la mayoría

Tabla No. 3. Adolescentes, por edad simple, según hijas/os nacidos vivos en la región occidental, 2001 (cifras absolutas y relativas)

\begin{tabular}{|c|c|c|c|c|c|c|c|c|c|c|}
\hline \multirow{3}{*}{ Edad } & \multicolumn{10}{|c|}{ Total de hijos nacidos vivos } \\
\hline & \multicolumn{5}{|c|}{ Total Regional } & \multicolumn{5}{|c|}{$\%$} \\
\hline & 1 & 2 & 3 & 4 & Total & 1 & 2 & 3 & 4 & Total \\
\hline 12 & 12 & - & - & - & 12 & 0.19 & - & - & - & 0.19 \\
\hline 13 & 15 & - & - & - & 15 & 0.23 & - & - & - & 0.23 \\
\hline 14 & 33 & - & - & - & 33 & 0.51 & - & - & - & 0.51 \\
\hline 15 & 195 & 15 & - & - & 210 & 3.01 & 0.23 & - & - & 3.24 \\
\hline 16 & 544 & 65 & - & - & 609 & 8.40 & 1.00 & - & - & 9.40 \\
\hline 17 & 958 & 173 & 26 & - & 1,157 & 14.79 & 2.67 & 0.40 & - & 17.86 \\
\hline 18 & 1,586 & 449 & 95 & - & 2,130 & 24.48 & 6.93 & 1.47 & - & 32.88 \\
\hline 19 & 1,465 & 689 & 128 & 31 & 2,313 & 22.61 & 10.63 & 1.98 & 0.48 & 35.70 \\
\hline Total & 4,808 & 1,391 & 249 & 31 & 6,479 & 74.21 & 21.47 & 3.84 & 0.48 & 100 \\
\hline
\end{tabular}

Fuente: Elaboración propia, con base a datos Redatam, INE, 2001 
de las adolescentes con alguna hija o hijo nacido vivo, no estudia en la actualidad, sólo el 5\% del total regional lo hace, lo cual hace evidente que la procreación en la adolescencia, coarta las posibilidades de superación de las jóvenes en todos los aspectos de la vida, porque deben abandonar sus estudios para asumir su nuevo rol como madres. A la vez, este hecho incidirá negativamente en su futuro papel de adulta puesto que su contribución al desarrollo de su departamento será mínima.

Las posibilidades de estudio para las jóvenes en la región no son muy alentadoras, dado que el sistema educativo nacional no cumple con la cobertura adecuada, tanto en infraestructura escolar como en equipo, para atender las necesidades de toda la población estudiantil; esto se hace evidente en el sentido de que, aún la mayoría de las jóvenes que no tienen hijas/os nacidos vivos no estudian actualmente, únicamente el 34\% en relación al total regional de la población femenina adolescente tiene acceso al sistema educativo; esta situación es preocupante, es vista de que, entre menor sea la escolaridad de las jóvenes, mayor será la incidencia del embarazo adolescente y el promedio de hijos/as (OPS, 1992).

Los tres departamentos presentan la misma tendencia, la mayoría de las jóvenes que estudian tienen sólo una hija o hijo en promedio; el 21\% tiene dos hijas/os nacidos vivos en promedio; las posibilidades de estudio para las jóvenes que tienen tres hijas o hijos en promedio son reducidas, más aún para las que tienen cuatro hijas o hijos, el promedio de las que estudian representa el 4 y $0.48 \%$ respectivamente (gráfico No. 15).

En la mayoría de los casos las jóvenes se ven obligadas no sólo a abandonar sus estudios sino también, a relegar el cuidado de los pequeños/as en otros familiares para dedicarse a actividades productivas de baja remuneración, en consecuencia, los niños/as crecen sin el cariño y afecto de sus progenitoras, causándoles a la larga problemas de autoestima y otros que no les permite desarrollar plenamente todas sus potencialidades y capacidades humanas, interfiriendo al mismo tiempo, en su inserción definitiva a la sociedad de la cual forman parte.
Adolescentes de los pueblos indígenas que actualmente estudian: Al comparar las jóvenes lenca y chortí con el resto de jóvenes de la región occidental, notaremos que la tendencia es similar en los tres departamentos; los valores de las jóvenes con hijos/as que actualmente estudian son mínimos, casi la totalidad de ellas no estudia actualmente; sin embargo, el porcentaje de las jóvenes que no tiene hijos/as y que no estudia actualmente también es muy elevado en toda la zona (gráfico No. 16).

Según el total de hijas/os nacidos vivos, las jóvenes indígenas presentan una tendencia similar con el resto de adolescentes de la región occidental del país, a diferencia del valor de las adolescentes con dos hijos/as en promedio, que representa dos puntos arriba en las jóvenes indígenas.

Gráfico No. 15. Porcentaje de adolescentes que actualmente estudian, según el total de hijas/os nacidos vivos, en relación al total regional, de la zona occidental de Honduras, 2001

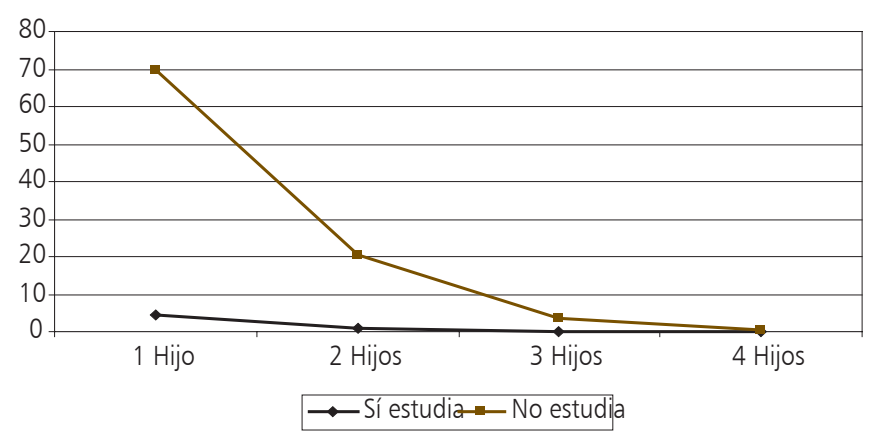

Fuente: Elaboración propia, con base a datos Redatam, INE, 2001

Gráfico No. 16. Porcentaje de población adolescente que actualmente estudia, según hijo nacido vivo y grupo poblacional, en la zona occidental de Honduras, 2001

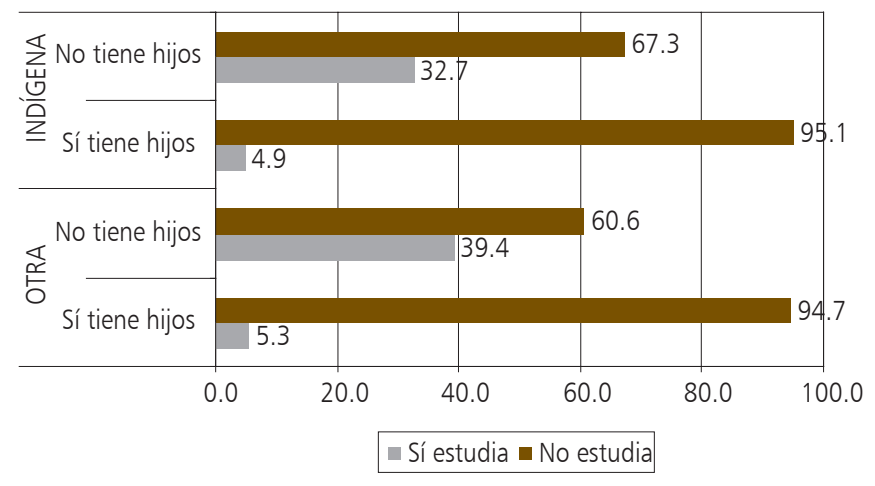

Fuente: Elaboración propia, con base a datos Redatam, INE, 2001 
Lo anterior confirma que existe una relación directa entre el inicio de la procreación temprana y el abandono de los estudios, sin importar el grupo poblacional al que pertenezcan las jóvenes (gráfico No. 17).

Adolescentes que actualmente estudian por área de residencia urbana y rural: Los casos de embarazo en la adolescencia son mayores en el área rural que en la urbana, la tendencia se mantiene similar en los tres departamentos; podemos observar que el porcentaje de las adolescentes que tienen hijos/as en relación al total por área de residencia, es del 9\% para el área urbano y del 12\% para el área rural. Aunque el porcentaje de las

Gráfico No. 17. Adolescentes que actualmente estudian, en porcentaje según el total de hijas/os nacidos vivos y grupo poblacional, en relación al total regional de la zona occidental de Honduras, 2001

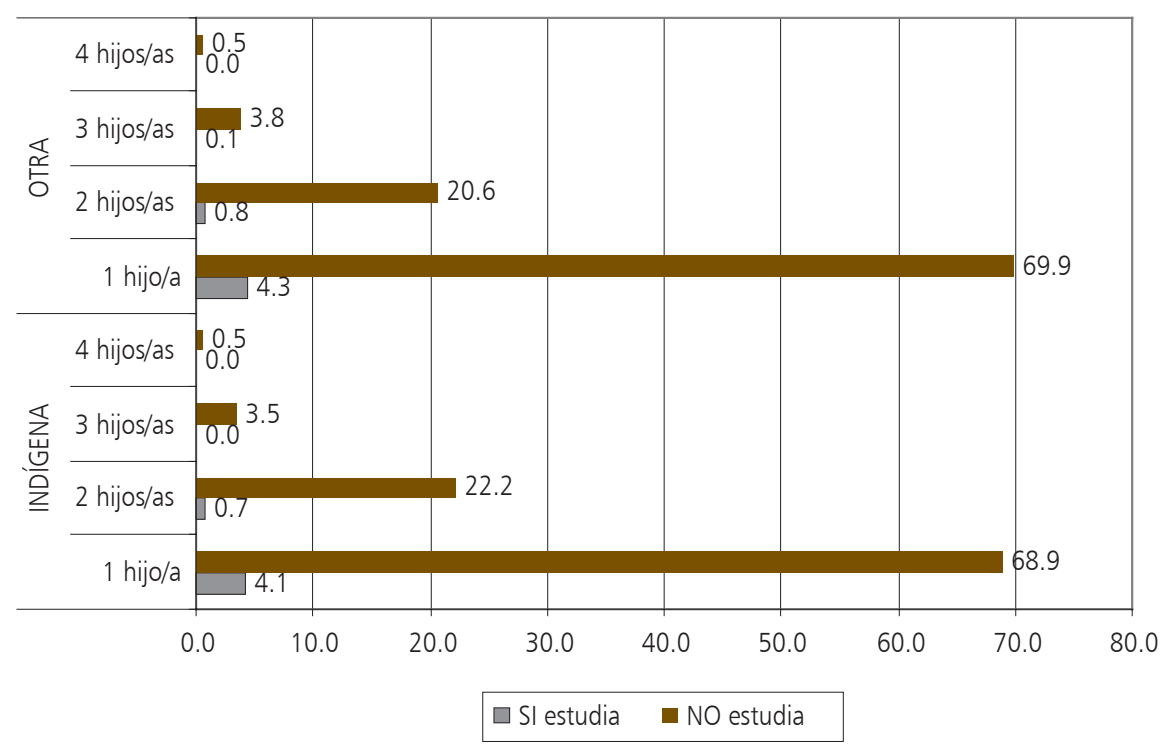

Fuente: Elaboración propia, con base a datos Redatam, INE, 2001

Tabla No. 4. Adolecentes que actualmente estudian, en porcentaje según el área de residencia, en los deptos de Copán, Lempira y Ocotepeque, 2001

\begin{tabular}{|c|c|c|c|c|c|c|c|c|c|}
\hline \multirow{4}{*}{$\begin{array}{l}\text { Actual- } \\
\text { mente } \\
\text { Estudia }\end{array}$} & \multicolumn{9}{|c|}{ Hija/o nacido vivo } \\
\hline & \multicolumn{9}{|c|}{ Copán, Lempira y Ocotepeque } \\
\hline & \multicolumn{3}{|c|}{ Urbano } & \multicolumn{3}{|c|}{ Rural } & \multicolumn{3}{|c|}{ Total } \\
\hline & Sí & No & Total & Sí & No & Total & Sí & No & Total \\
\hline sí & 1.18 & 59.30 & 60.48 & 0.45 & 27.92 & 28.37 & 0.59 & 33.68 & 34.27 \\
\hline No & 7.83 & 31.68 & 39.52 & 11.20 & 60.43 & 71.63 & 10.58 & 55.16 & 65.73 \\
\hline Total & 9.01 & 90.99 & 100 & 11.65 & 88.35 & 100 & 11.17 & 88.83 & 100 \\
\hline
\end{tabular}

Fuente: Elaboración propia, con base a datos Redatam, INE, 2001 jóvenes con alguna hija/o que estudian actualmente, es bastante bajo en ambas áreas, el del área urbana es levemente superior al de la rural, en esta última, casi la totalidad de las jóvenes con hijas/os no estudian actualmente, sólo el 0.45\% lo hace (tabla No. 4).

Las posibilidades de realizar estudios en el área urbana son mejores que las del área rural, tanto para las jóvenes que no tienen hijos/as como para las que si los tienen. Los valores de las jóvenes del área urbana que no tienen hijos y estudian actualmente es doblemente superior al del área rural con un $65.18 \%$, en cambio, sólo el 31.6\% de las jóvenes sin hijos del área rural estudia actualmente; pero la mayoría el 68.4\% de las jóvenes del área rural aún sin hijos/as no estudia actualmente (gráfico No. 18).

En relación al total regional, del $11 \%$ de las adolescentes tiene hijas/ os nacidos vivos, el $9.5 \%$ corresponde al área rural y el 1.6\% al área urbana. En ambas áreas, casi la totalidad de las jóvenes de la región con hijas/os el $10.58 \%$ no estudia actualmente; sólo estudia el $0.59 \%$ de las jóvenes en toda la región occidental; lo cual refleja que, las jóvenes que inician tempranamente la procreación, tienen menos oportunidades de continuar sus estudios, sobre todo si viven en el área rural y con mayor promedio de hijos e hijas (gráfico No. 19).

Adolescentes de los pueblos indígenas que actualmente estudian, por área de residencia urbana y rural: En comparación con el resto de las adolescentes de la región, las jóvenes indígenas se encuentran en una posición desfavorable, aunque un tanto similar, el porcentaje de las adolescentes indígenas que no estudia 
actualmente es del $70.37 \%$; sólo el 29.63\% estudia en su mayoría son las jóvenes que no tienen hijos/as; sólo 0.54\% de las jóvenes con hijos/as estudia. Debido a qué, la mayoría de la población indígena esta ubicada en el área rural, las jóvenes indígenas son las menos favorecidas, deben realizar grandes recorridos en caminos en malas condiciones y con todos los riesgos que conlleva para llegar al centro educativo más cercano (gráficos No. 20, 21).

Último grado, curso o año aprobado: El nivel de escolaridad predominante en las jóvenes según el total de hijas/os nacidos vivos, es el nivel primario, en vista de que al iniciar la procreación, las jóvenes optan por abandonar sus estudios, no obstante el derecho de las adolescentes a continuar sus estudios aún en condiciones de embarazo; la tendencia es similar en toda la región.

Las jóvenes que incrementan el promedio de hijas o hijos nacidos vivos, son por lo general las jóvenes del nivel primario y las analfabetas, lo cual hace imprescindible desarrollar proyectos encaminados a brindar orientación a todas las jóvenes, a fin de persuadirlas de no interrumpir sus estudios, en vista que, entre menor sea la escolaridad mayores serán las probabilidades de incrementar el promedio de hijos y entre mayor sea el promedio de hijos, menos posibilidades tienen de continuar sus estudios en niveles más avanzados (gráfico No. 22).

\section{Último grado, curso o año apro-} bado por las adolescentes indígenas: En cuanto al nivel de escolaridad, las jóvenes indígenas presentan tendencias similares al resto de las jóvenes de la región; en su mayoría, el último grado aprobado tanto para las que tiene hijos/as como para las que no los tienen esta a nivel de educación primaria. El segundo promedio más alto, corresponde a las jóvenes que no tienen ningún nivel educativo, sobre todo en las jóvenes que tienen hijos/as; la tendencia es similar en ambos grupos poblacionales pero las
Gráfico No. 18. Adolecentes que actualmente estudian, en porcentaje según hija/o nacido vivo y área de residencia en los deptos de Copán, Lempira y Ocotepeque, 2001

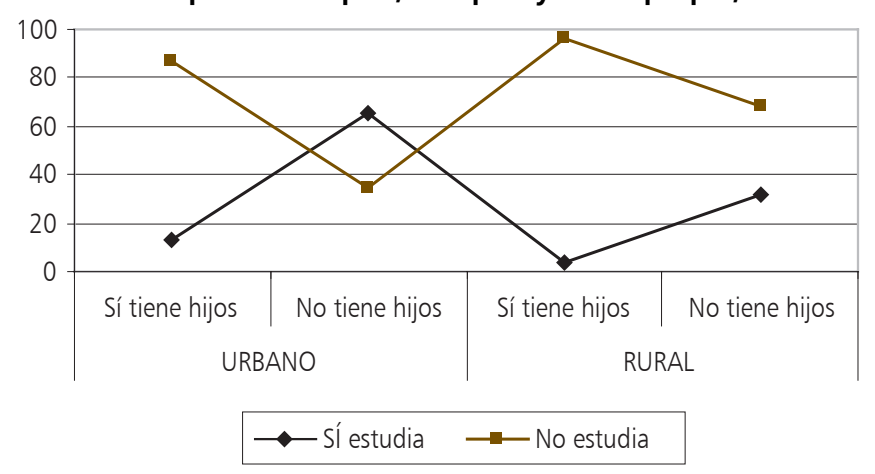

Fuente: Elaboración propia, con base a datos Redatam, INE, 2001

Gráfico No. 19. Adolescentes que actualmente estudian, en porcentaje según hija/o nacido vivo y área de residencia, en relación al total regional de la Zona Occidental de Honduras, 2001

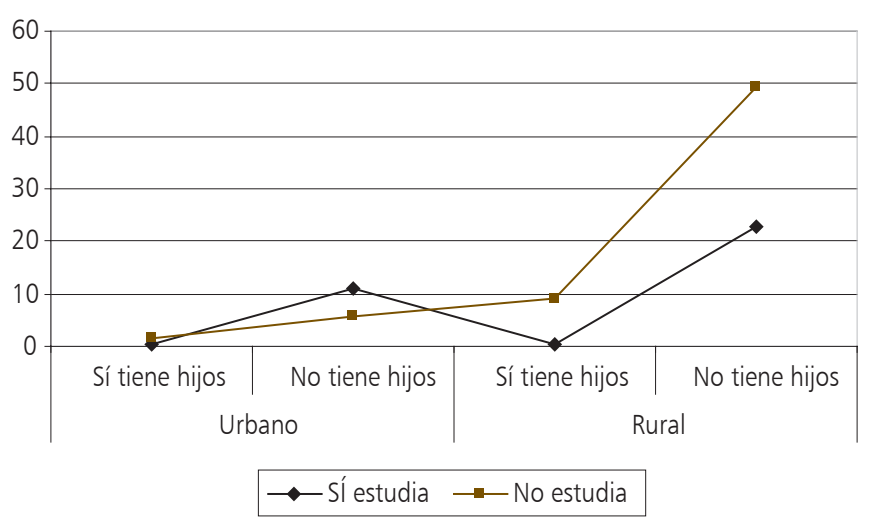

Fuente: Elaboración propia, con base a datos Redatam, INE, 2001

Gráfico No. 20. Adolescentes que actualmente estudian, en porcentaje según hija/o nacido vivo, grupo poblacional y área de residencia, en relación al total regional de la Zona Occidental de Honduras, 2001

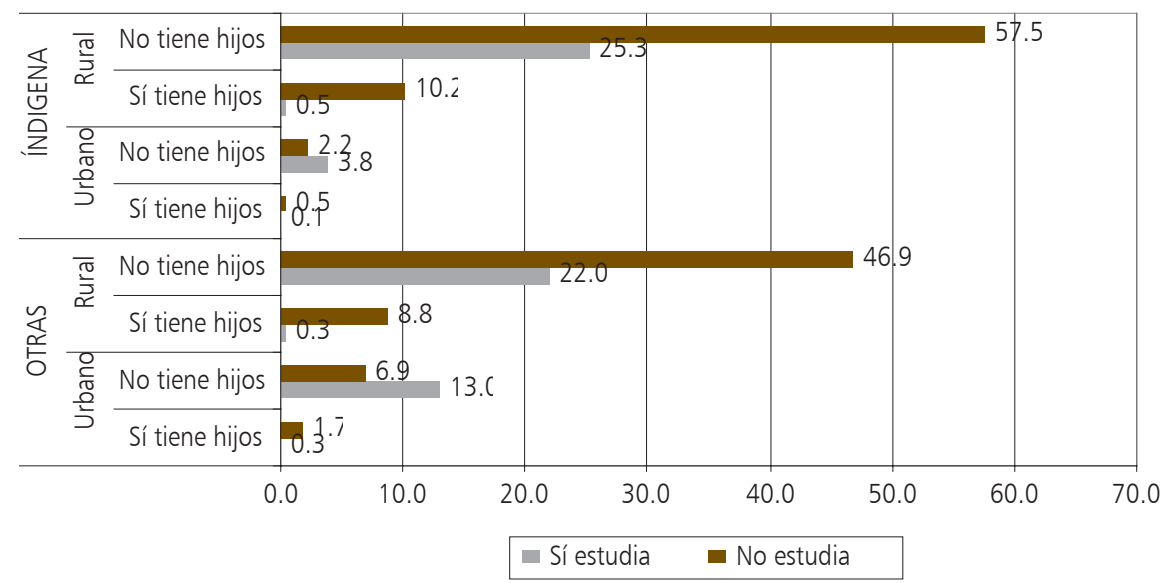

Fuente: Elaboración propia, con base a datos Redatam, INE, 2001 
Gráfico No. 21. Porcentaje de adolescentes indígenas que actualmente estudian, según hija/o nacido vivo y área de residencia, en relación al total indígena regional de la Zona Occidental de Honduras, 2001

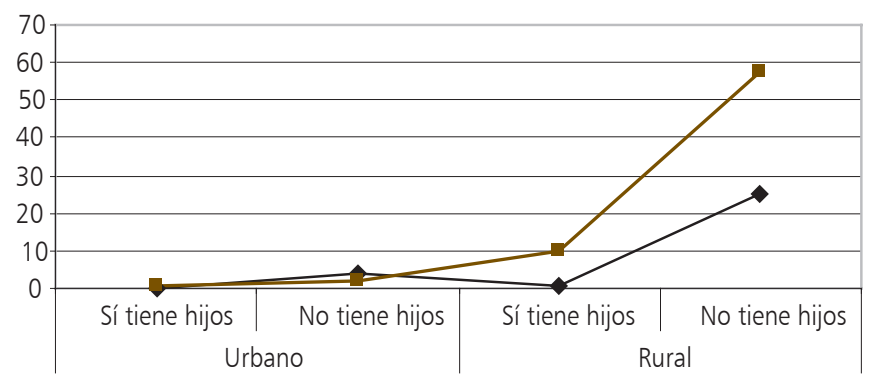

$\longrightarrow$ Sí estudia $\longrightarrow$ No estudia

Fuente: Elaboración propia, con base a datos Redatam, INE, 2001

Gráfico No. 22. Porcentaje de adolescentes, según el total de hijas/os nacidos vivos y nivel educativo, en la Zona Occidental de Honduras, 2001

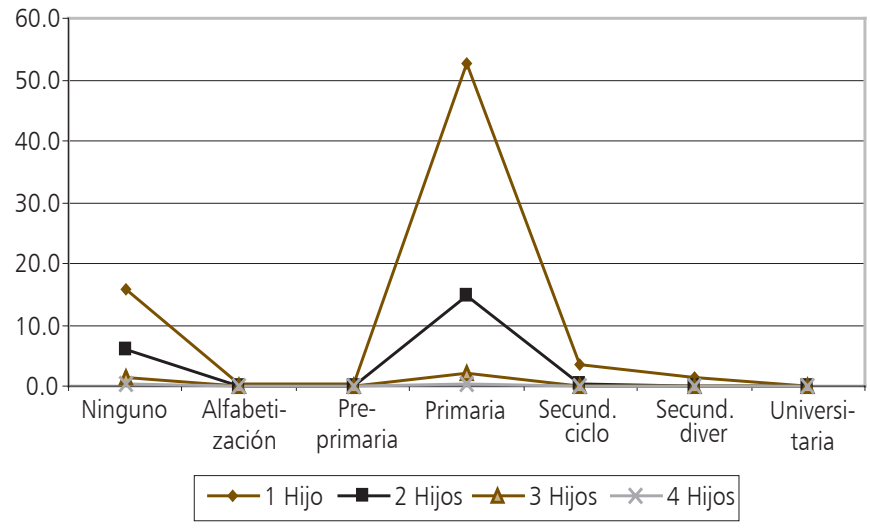

Fuente: Elaboración propia, con base a datos Redatam, INE, 2001

Gráfico No. 23. Nivel educativo de adolescentes, en porcentaje según grupo poblacional e hijas/os nacidos vivos, en la Zona Occidental de Honduras, 2001

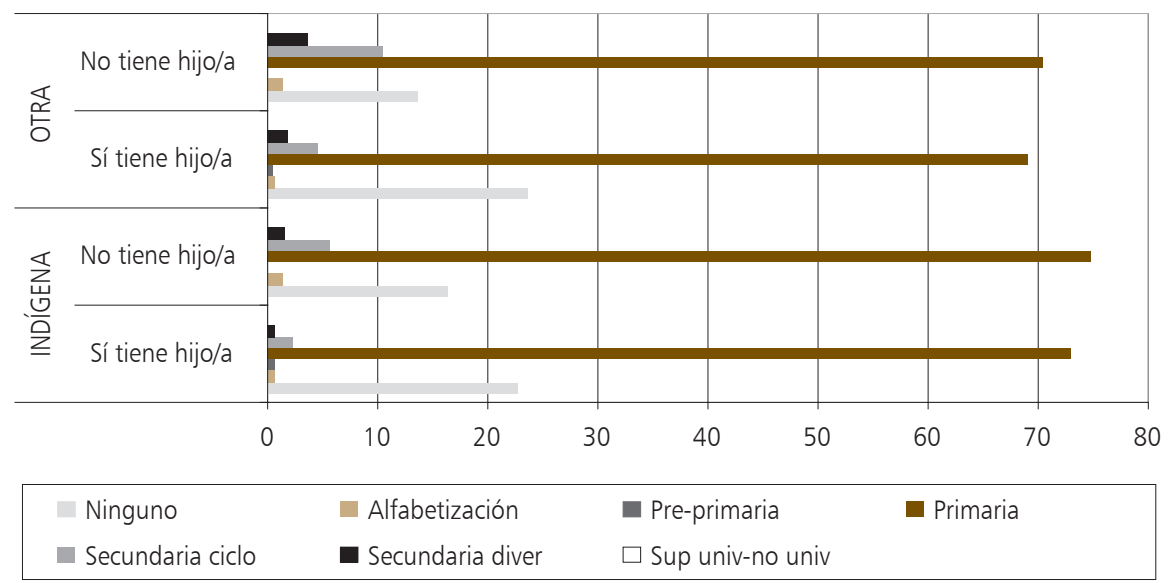

Fuente: Elaboración propia, con base a datos Redatam, INE, 2001 condiciones de escolaridad son más desfavorables para las jóvenes indígenas (gráfico No. 23)

Último grado, curso o año aprobado por las adolescentes, según el área de residencia urbana y rural: La tendencia es similar en ambas áreas de residencia, el último grado aprobado de la mayoría de las jóvenes tanto las que tienen hijos/as como las que no los tienen, es a nivel primario; las jóvenes residentes en el área urbana, tienen mejores oportunidades para continuar sus estudios secundarios y diversificado, aunque los valores más altos los presentan las jóvenes que no tienen hijos/as, las que si los tienen, presentan un mejor nivel educativo que las jóvenes del área rural. El promedio más alto en analfabetismo en ambas áreas de residencia, lo representa las jóvenes con hijos/as; sobre todo las que viven en el área rural doblan el valor de las que viven en el área urbana con un $25.17 \%$, aún el promedio de las jóvenes sin hijos del área rural es más elevado que las jóvenes de la urbana (gráfico No. 24).

La situación educativa de las jóvenes del área rural según el promedio de hijos/as, es más crítica, el nivel de escolaridad de la mayoría de las jóvenes independientemente del promedio de hijos/as, es el nivel primario; sólo el 1.8\% de las jóvenes que tienen un hijo/a en promedio, alcanza la secundaria, además, los valores de analfabetismo son mayores que los del área urbana; las adolescentes con promedio de dos, tres y cuatro hijos/as, no continúan sus estudios secundarios (gráfico No. 25).

Último grado, curso o año aprobado por las adolescentes indígenas, según el área de residencia urbana y rural: La tendencia del último grado, curso o año aprobado de las jóvenes indígenas, es similar a la del resto de jóvenes en la región; las jóvenes que tienen hijos/as presentan los valores más bajos en los diferentes niveles educativos, asimismo, les corresponden los valores más altos en analfabetismo, sobre todo si pertenecen a 
los pueblos indígenas; las jóvenes en ambos grupos poblacionales que no tienen hijos/as y que viven en el área urbana, son las que poseen los niveles educativos más altos en la región (gráfico No. 26).

Las jóvenes de ambos grupos poblacionales que viven en el área rural, presentan los niveles educativos más bajos en la región, el nivel educativo de la mayoría de las jóvenes, tanto las que tienen hijos/as como las que no los tienen, es el nivel primario, seguido de las jóvenes que no tienen ningún nivel educativo, presentando los valores más altos en analfabetismo, las jóvenes de ambos grupos poblacionales que tienen hijos/as. Los valores en los demás niveles educativos son bastante bajos, situación preocupante si se toma en cuenta que la población de la región occidental es eminentemente rural, sobre todo la población indígena (gráfico No. 27).

Aportación laboral: En Honduras, las cifras del trabajo infantil y adolescente son elevadas a pesar de la existencia de una gran variedad de instrumentos legales orientados hacia la erradicación del mismo; según la Encuesta de Trabajo Infantil de la Encuesta Permanente de Hogares de Propósitos Múltiples (EPHPM) del año 2002, el 16.9\% de niños y niñas de $10-14$ y el $40.5 \%$ de entre los 15 17 años estaban ocupados; el trabajo infantil y adolescente en ambos sexos, se manifiesta mayormente en el área rural, representando un $34.5 \%$ y sólo el $18.2 \%$ del área urbana. La edad
Gráfico No. 24. Nivel educativo de adolescentes, en porcentaje según hija/o nacido vivo y área de residencia, Zona Occidental de Honduras, 2001

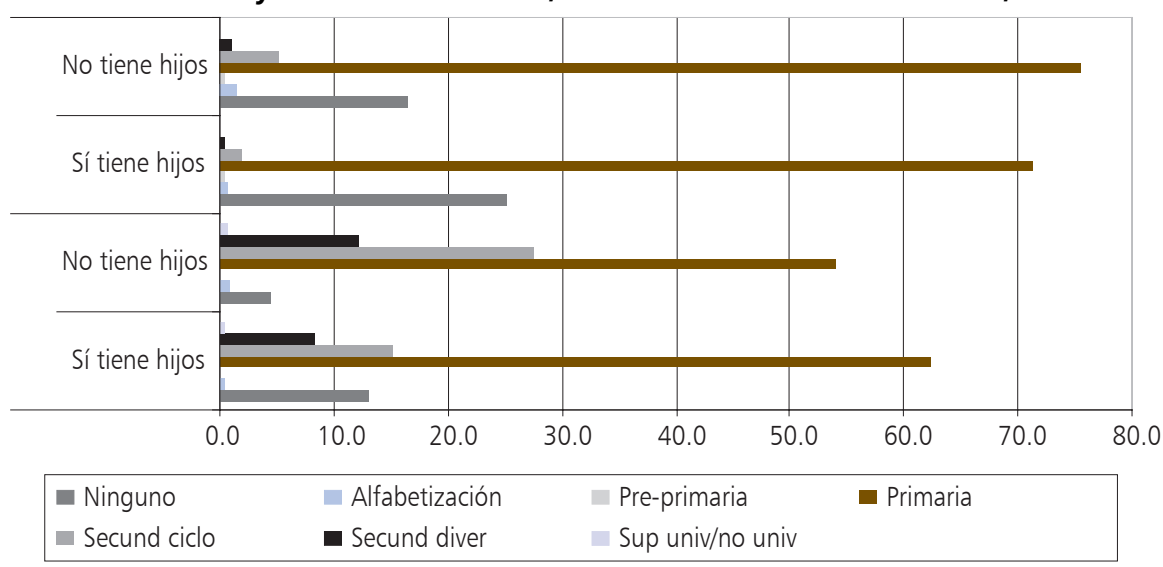

Gráfico No. 25. Nivel educativo de adolescentes, en porcentaje según el total de hijas/os nacidos vivos y el área rural, de la Zona Occidental de Honduras, 2001

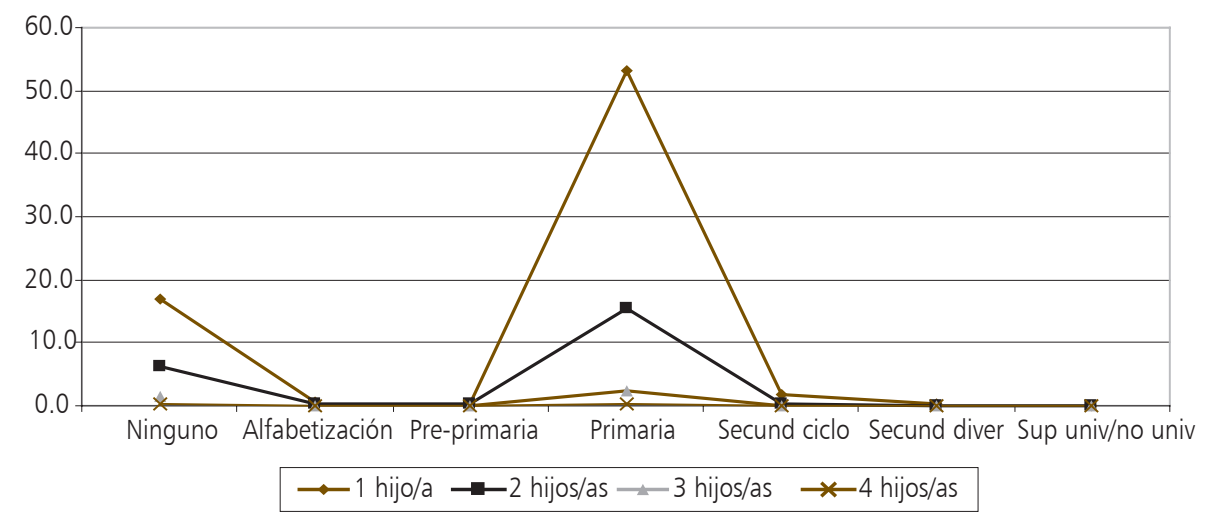

Fuente: Elaboración propia, con base a datos Redatam, INE, 2001

Gráfico No. 26. Nivel educativo de adolescentes, en porcentaje según grupo poblacional, hija/o nacido vivo y área urbana de la Zona Occidental de Honduras, 2001

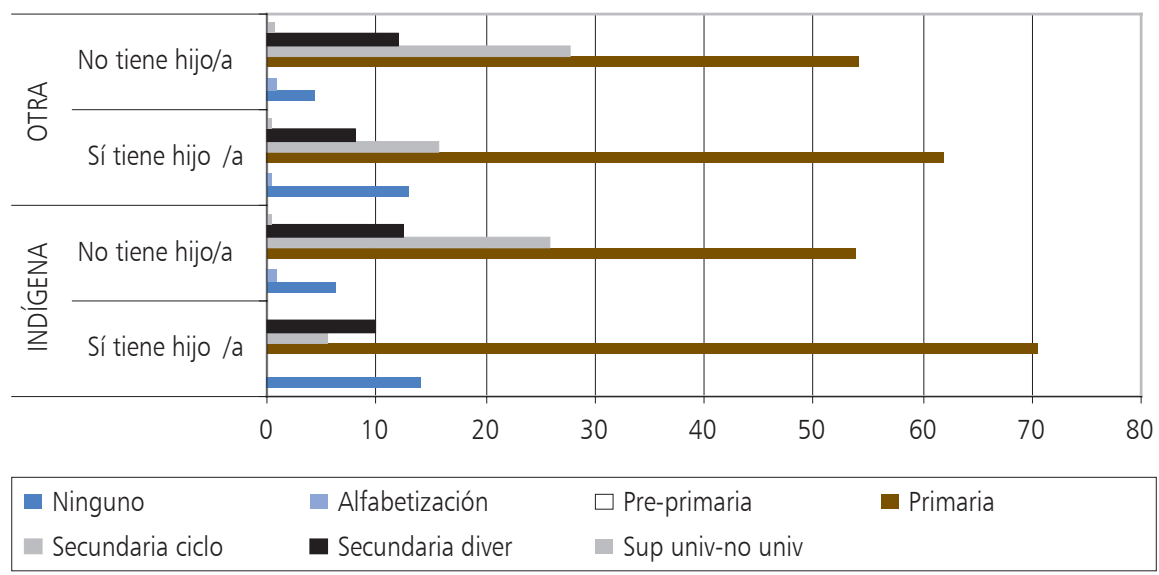

Fuente: Elaboración propia, con base a datos Redatam, INE, 2001 
promedio de los niños/as y adolescentes ocupados/as de 5-17 años para el 2002 fue de 14 años; 14.4 años para el área urbana y 13.9 años para el área rural.

Principal rama de actividad: En toda la región, la mayoría de las adolescentes que trabajan son las que no tienen hijos/as nacidos vivos; el aporte laboral de las que tienen hijos/as es sólo del 10.3\% del total, desarrollando actividades principalmente en la industria manufacturera y en los servicios comunales, sociales y personales. Las

Gráfico No. 27. Nivel educativo de adolescentes, en porcentaje según grupo poblacional, hija/o nacido vivo y área rural de la Zona Occidental de Honduras, 2001

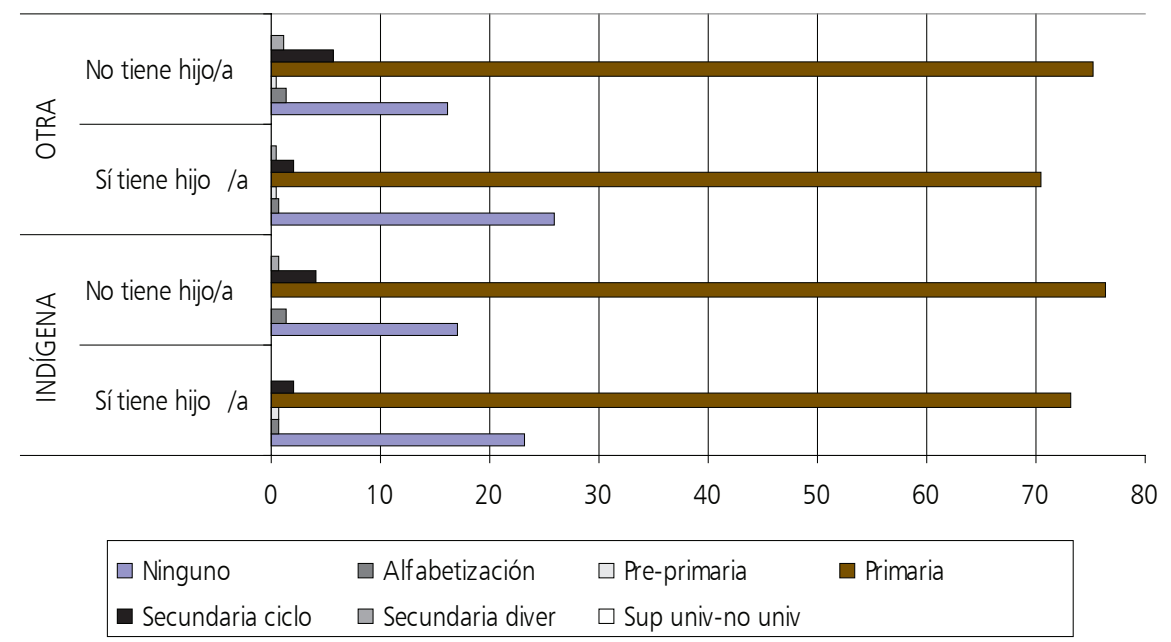

Fuente: Elaboración propia, con base a datos Redatam, INE, 2001

Gráfico No. 28. Porcentaje de adolescentes, según hijo/a nacido vivo y rama de actividad, en la Zona Occidental de Honduras, 2001

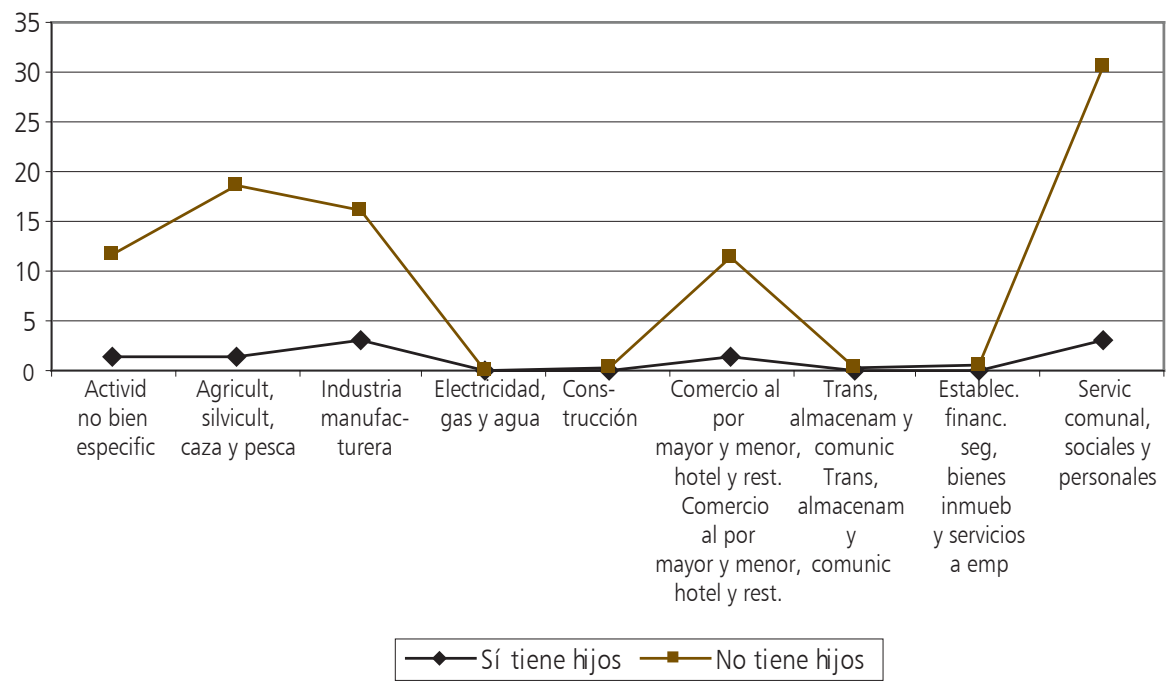

Fuente: Elaboración propia, con base a datos Redatam, INE, 2001 jóvenes que tienen un solo hijo/a en promedio son las que normalmente trabajan, entre más aumenta el promedio de hijos, menor es su participación en actividades productivas y mayor su dependencia económica (gráfico No. 28).

Principal rama de actividad de las adolescentes indígenas: Las actividades que realizan las jóvenes lenca y chortí estan orientadas a la agricultura, silvicultura, caza y pesca y en segundo lugar a la prestación de servicios comunales, sociales y personales. Al igual que el resto de jóvenes de la región, las jóvenes indígenas que no tienen hijos/as son las que, por lo general realizan actividades productivas, la participación de las que tienen hijos/as es mínima.

Principal rama de actividad por área de residencia urbana y rural: Las adolescentes que tienen hijas/os nacido vivo en ambas áreas de residencia, son la que menos se incorporan al medio laboral, su aportación es mínima en comparación con las que no tienen hijos/as, son éstas, las que están más involucradas al trabajo productivo. Las principales actividades que realizan en orden de importancia son: la prestación de servicios, el desarrollo comercial y la manufactura en el área urbana; las actividades agrícolas, la prestación de servicios y la industria manufacturera en el área rural. El porcentaje de las jóvenes que se dedican a la realización de actividades no bien especificadas, es mayor en el área rural que en la urbana y el desarrollo comercial es mayor en el área urbana que en la rural.

Principal rama de actividad de las adolescentes indígenas por área 
de residencia urbana y rural: Las principales actividades que desarrollan las jóvenes indígenas en el área urbana, son similares a las que realizan el resto de jóvenes en la región; la mayoría de jóvenes indígenas que se incorporan al mercado laboral, son las que no tienen hijos/as; la participación de las que tienen hijos/as es mínima. En el área rural, predominan las actividades agrícolas en ambos grupos poblacionales; otras actividades de importancia son las relacionadas con la industria manufacturera y la prestación de servicios comunales, sociales y personales.

Desempeño de las adolescentes por área de residencia: Las jóvenes que no tienen hijos/as del área urbana y sobre todo las que viven en Copán, son las que tienen mayor oportunidad de desempeñarse como empleadas u obreras privadas y en oficios domésticos, en menor porcentaje se desempeñan como trabajadoras independientes. En Lempira y Ocotepeque, el desempeño de las jóvenes se limita al trabajo doméstico, los salarios de este tipo de trabajo son bastante bajos, debido a que, no se reconoce como actividad productiva en el sistema capitalista.

La situación del área rural es similar a la del área urbana, las jóvenes que tienen mayor desempeño, son las que no tienen hijos/as, a diferencia del área urbana, las principales actividades en que se desempeñan en los tres departamentos, sobre todo en Lempira, es en el trabajo familiar, por lo general este tipo de trabajo no es remunerable por considerarse un aporte para el sustento familiar. Otro desempeño en importancia es el trabajo independiente y el doméstico.

\section{COMPROBACIÓN DE HIPÓTESIS:}

El matrimonio/unión precoz tiene mayor preponderancia entre las jóvenes adolescentes del área rural con bajos niveles de escolaridad: Hay mayor proporción de jóvenes casadas y unidas en el área rural que la urbana; dentro de las medidas de tendencia central, la moda entre las adolescentes del área rural, es la unión libre, una vez que las jóvenes se casan o se unen precozmente, están mas expuestas al riesgo del embarazo, además, al iniciar la procreación la mayoría de ellas interrumpe sus estudios.

El nivel educativo, influye de manera determinante para incrementar el embarazo en las adolescentes, sin embargo, considerando que los niveles de pobreza son altos en el país y sobre todo en los departamentos donde se hace el estudio, muchas jóvenes optan por trabajar antes que estudiar, en consecuencia, no tienen los suficientes conocimientos para tomar decisiones que marcarán su vida para siempre, en ese sentido, el papel de los padres de familia es fundamental no sólo para asegurar la escolaridad de las jóvenes sino también para orientarlas adecuadamente.

Otros estudios han demostrado que una de las razones por las que muchas adolescentes se unen en matrimonio o en unión consensual, es precisamente por buscar seguridad económica, la que obtienen al unirse a hombres adultos, iniciando así, el proceso de dependencia que por lo regular, no les permite desarrollar sus potencialidades humanas.

La procreación temprana esta influenciada por el área de residencia y por el nivel educativo de las adolescentes: Al haber mayor proporción de adolescentes casadas y en unión en el área rural, también la procreación temprana es mayor debido principalmente a su exposición al riesgo del embarazo; al mismo tiempo, al obtener los niveles de escolaridad más bajos, tienen menores oportunidades de informarse adecuadamente para ejercer sus derechos reproductivos en forma responsable. Las jóvenes analfabetas y las de menor nivel educativo, son las que normalmente incrementan la proporción de hijas/os nacidos vivos.

La temprana ocupación de las adolescentes repercute en el inicio de la procreación: Debido a que el sistema educativo nacional no es lo suficientemente efectivo para brindar cobertura en cantidad y calidad, sobre todo en el área rural y a la situación de pobreza persistente en la región, muchas adolescentes optan por abandonar sus estudios e incorporarse al ámbito laboral, no obstante, al abandonar los estudios no se capacitan 
adecuadamente, reduciendo sus opciones a la realización de actividades que requieren poca especialización y por tanto, los ingresos para la subsistencia son mínimos.

El nivel educativo de la mayoría de las adolescentes con o sin hijas o hijos, es a nivel primario y las actividades ocupacionales que realizan no requieren necesariamente de especialización, están dirigidas hacia la prestación de servicios comunales, sociales y personales; la industria manufacturera; la agricultura, silvicultura, pesca; el comercio al por mayor y menor; estas actividades normalmente tienen una baja remuneración que no permite cubrir las necesidades básicas, asimismo, las jóvenes que se dedican a otros trabajos que por su naturaleza son independientes y los de tipo familiar, reciben aún ingresos más bajos o no los reciben.

Las jóvenes que realizan alguna actividad productiva, son en su mayoría las que no tienen hijas/os nacidos vivos, esto demuestra que, entre más involucradas estén las jóvenes en el ámbito laboral, menos posibilidades tendrán de incrementar su nivel educativo. La temprana inserción laboral repercute entonces, por un lado, al estancamiento en la formación y capacitación de las jóvenes y por otro, los bajos salarios para cubrir sus necesidades básicas son insuficientes, esto conlleva a la dependencia económica de los hombres y en consecuencia, al embarazo precoz.

La participación de las jóvenes que tienen hijas o hijos nacidos vivos en el mercado laboral, es mínima y casi la totalidad de ellas sólo tiene una/un hijo en promedio, al igual que las jóvenes sin hijos, el nivel educativo es a nivel primario y con baja especialización, por lo que, la forma de inserción laboral es similar.

Considerando el alto porcentaje de madres solteras adolescentes, un $20.4 \%$ en toda la región, se puede deducir que, debido a la paternidad irresponsable son estas jóvenes las que se insertan al mercado laboral; las jóvenes con estado civil casada y en unión libre, normalmente se dedican al trabajo doméstico, la crianza de los hijos o en última instancia al trabajo de índole familiar, ante estas circunstancias las libertades básicas humanas y las opciones de vida para estas jóvenes se ven reducidas al máximo.
Unido a lo anterior, la falta de información, orientación, educación, asesoramiento y privación de los Derechos Sexuales y Reproductivos de las jóvenes repercutirá en el inicio de la procreación precoz, en los períodos intergenésicos cortos, en el posterior abandono del mercado laboral y en el desarrollo de obligaciones de adulta siendo aún niñas, sin la correspondiente preparación profesional, madurez psíquica y emocional que lejos de desarrollar su potencial humano contribuye a su empobrecimiento.

Cuando el nivel educativo y de especialización de la mujer es alto, tiene mayores oportunidades al insertarse al mercado laboral, mejores ingresos y las posibilidades para iniciar la procreación temprana o incrementar el promedio de hijas o hijos son menores, asimismo, los períodos intergenésicos se vuelven más largos facilitando su educación integral para el logro de mejor calidad vida para ellas, sus hijas e hijos y así, convertirse en factores claves para el desarrollo a nivel comunitario y nacional.

La incidencia del embarazo en la adolescencia es mayor en las jóvenes indígenas: La hipótesis es negativa, debido a que la tendencia de la fecundidad de las adolescentes indígenas, es similar a la del resto de las adolescentes en los tres departamentos, tanto en las que no tienen hijas/os nacidos vivos, como en las que los tienen, así como en el promedio de hijos por joven.

En toda la región, el departamento de Lempira es el que tiene mayor población femenina adolescente indígena, sin embargo, el porcentaje de las jóvenes indígenas con hijos e hijas es menor que el de las demás jóvenes; el departamento de Copán es el que cuenta con menor población indígena, pero es el que presenta el mayor número de casos de embarazo adolescente, al igual que, el incremento en el promedio de hijas o hijos por adolescente.

\section{CONCLUSIONES}

Según la tasa de crecimiento, para los próximos años se incrementará el número de población femenina adolescente, con ello, se elevan las probabilidades del 
embarazo adolescente en muchos casos no deseado, uniones y matrimonios precoces, con el consiguiente crecimiento poblacional.

El departamento de Copán es el que presenta los valores más altos de adolescentes con hijos/as nacidos vivos, además, el que presenta los problemas más graves de analfabetismo, por lo que, las jóvenes a esta edad, no tienen la madurez suficiente para brindarle a sus hijos/as los cuidados adecuados tanto en salud, como en educación y orientación en valores para la formación de nuevos ciudadanos/as con calidad, que contribuyan al desarrollo de sus comunidades.

El incremento del embarazo en las adolescentes, generalmente ocurre a partir de los 15 años; el inicio temprano de las uniones conyugales sin orientación, aumentan las probabilidades de un embarazo precoz ya que, en la región occidental, la experiencia sexual de las jóvenes de entre 15-24 años, es mayor que a nivel nacional y los programas actuales con respecto a la salud reproductiva orientados para las adolescentes aún no brindan resultados idóneos que contribuyan a la disminución del problema del embarazo temprano.

El nivel educativo de la mayoría las adolescentes con hijas o hijos nacidos vivos es a nivel primario, en la mayoría de los casos, al iniciar la procreación las jóvenes abandonan sus estudios, las que junto con las jóvenes analfabetas son las que incrementan el número de hijos, este hecho incidirá negativamente en su futuro papel de adulta puesto que su contribución al desarrollo de su departamento será mínima.

Sólo el 5\% de las adolescentes con hijas o hijos nacidos vivos estudia actualmente, la mayoría de ellas tiene un hijo/a en promedio, las demás jóvenes con hijos/as abandonan sus estudios para dedicarse a la maternidad, indicándonos que existe una relación directa entre el inicio de la procreación y la interrupción de los estudios de las jóvenes; situación que no les permite profesionalizarse y/o capacitarse para desarrollar sus potencialidades humanas, contribuyendo así, al inicio del círculo de la pobreza, del proceso de dependencia económica y finalmente la marginación.
Las posibilidades de estudio para las jóvenes en la región no son muy alentadoras, dado que el sistema educativo nacional no cumple con la cobertura adecuada, tanto en infraestructura escolar y equipo como en calidad, para atender las necesidades de toda la población estudiantil; esto se hace evidente en el sentido de que, aún la mayoría de las jóvenes que no tienen hijas/os nacidos vivos no estudian actualmente, sin importar el grupo poblacional al que pertenezcan.

En el área urbana, las jóvenes que tienen en promedio un solo hijo/a son las que tienen más facilidades de continuar sus estudios, pero las oportunidades se reducen para las que tienen dos o más hijos/as en promedio, en consecuencia, las oportunidades laborales disminuyen así como la obtención de ingresos dignos que contribuyan al desarrollo personal y al rompimiento del círculo de la pobreza.

El 20.4\% de las jóvenes son madres solteras, fenómeno más ocurrente en el área urbana que en la rural, lo cual evidencia que la paternidad irresponsable se manifiesta aún cuando se trata de niñas adolescentes, quienes se transforman posteriormente en jefas de hogar, teniendo la responsabilidad total del cuidado y la satisfacción de las necesidades básicas, viviendo en condiciones de pobreza y precariedad junto a sus hijos.

El promedio de hijas o hijos de las adolescentes, presenta una tendencia similar en los tres departamentos, este se incrementa independientemente del estado conyugal, un incremento mayor ocurre a partir de los 16 años, lo cual define un patrón muy fuerte para el fenómeno lo que hace necesario tomar medidas pertinentes al respecto de forma inmediata, en vista de que, se evidencia la falta de orientación y el desarrollo de efectivos programas con respecto a la Salud Sexual y Reproductiva.

En toda la región occidental, el fenómeno del embarazo en adolescentes y los promedios más altos en el número de hijos/as se manifiesta mayoritariamente en área rural, siendo predominante en ambas áreas de residencia el estado conyugal en unión libre.

La tendencia de las variables de fecundidad en las jóvenes indígenas es similar al resto de las adolescentes 
de la región, la mayoría de las jóvenes tienen un hijo/a en promedio, igualmente, una vez iniciada su vida conyugal, el incremento del número de hijos/as es evidente.

El departamento de Lempira, es el que tiene mayor población indígena femenina adolescente, pero el porcentajes del madres adolescentes indígenas, es más bajos que el del resto de jóvenes del departamento.

El nivel educativo de las jóvenes indígenas, presenta una situación similar al resto de las jóvenes de la región, pero con particularidades más profundas, debido a su ubicación en el área rural, por lo disperso de los poblados y por la poca cobertura del sistema educativo; la mayoría de ellas, sobre todo las jóvenes que tienen hijos/as, presenta los valores más bajos en los diferentes niveles educativos en toda la región.

Las adolescentes lenca, superan los valores de las adolescentes chortí con respecto al promedio de hijas/os nacidos vivos, que por el hecho de estar ubicadas en el departamento de Lempira, su situación se agrava, por ser este el departamento más pobre del país, ya que, las adolescentes mantienen total dependencia social y económica de su familia, por consiguiente, se fortalece el ciclo de la pobreza.

Las principales actividades en las que se desempeñan las jóvenes, requieren poca especialización por ello, la remuneración salarial es bastante baja; las jóvenes que tienen mayor participación en el mercado laboral son las que no tienen hijos/as, no obstante, son las más propensas al inicio de la procreación temprana debido a los bajos niveles educativos y a la escasa orientación en temas de Salud Sexual y Reproductiva, en consecuencia, se incrementa el promedio de hijos e hijos, se reduce su participación en el ámbito laboral, se incrementa su dependencia económica y el empobrecimiento.

Las actividades que realizan las jóvenes indígenas son semejantes a las que realizan las demás jóvenes de la región; la diferencia radica en que, su principal actividad esta orientada a la agricultura, silvicultura, caza y pesca y en segundo lugar a la prestación de servicios comunales, sociales y personales; la situación para el resto de las jóvenes de la región es a la inversa, coincidiendo en las actividades de la industria manufacturera como tercera actividad en importancia.

Las principales actividades que realizan las jóvenes por área de residencia, en toda la región, según el orden de importancia son: la prestación de servicios, el desarrollo comercial y la manufactura en el área urbana; las actividades agrícolas, la prestación de servicios y la industria manufacturera en el área rural.

En la región occidental, las jóvenes del área urbana y sobre todo las que viven en Copán, son las que tienen mayor oportunidad de desempeñarse como empleadas u obreras privadas y en oficios domésticos, en menor porcentaje se desempeñan como trabajadoras independientes; en el área rural, sobre todo en Lempira, se desempeñan en el trabajo familiar; como trabajadoras independientes y domésticas.

\section{BIBLIOGRAFÍA}

Alan Guttmacher Institute, 2003, Centers for Disease Control and Prevention y Family Care Interntional. Citado por el UNFPA, Estado de la población.

Banguero, Harold, 2000 La Transición Demográfica en Honduras, Documento de Trabajo, Maestría en Demografía Social, PLATS/ UNAH, Tegucigalpa, Honduras.

Bay, Guiomar, 2003, Determinantes próximos de la fecundidad. Una aplicación a países Latinoamericanos, serie Población y Desarrollo, CELADE, Naciones Unidas, Santiago de Chile.

Chackiel, Juan, 2004, La dinámica demográfica en América Latina, serie población y desarrollo, CELADE, División de Población, Naciones Unidas, Santiago de Chile.

Comisión Nacional para el Desarrollo de los Pueblos Indígenas, 2003, Convenio 169 de la OIT sobre Pueblos Indígenas y Tribales en Países Independientes, México.

Consejo Nacional de Población, 1998, Antología de la sexualidad humana, 1ra. De. México 1994, pp.29, 302 y 704, citado por, Secretaría de Salud Pública, Departamento de Salud MaternoInfantil, Unidad de Atención integral al escolar y al adolescente, Bases programáticas Programa de atención integral a la adolescencia, Tegucigalpa, Honduras.

Fondo de Naciones Unidas para Actividades en Población, 1998, Populi, Revista, Vol. 22, No. 7, septiembre de 1995, p. 24, citado por Secretaría de Salud Pública, Departamento de Salud MaternoInfantil, Unidad de Atención integral al escolar y al adolescente, Bases programáticas Programa de atención integral a la adolescencia, Tegucigalpa, Honduras.

Guzmán, José Miguel, 2001, Diagnostico sobre salud sexual y reproductiva en adolescentes en América Latina y el Caribe, UNFPA 1ํ. Edición México.

Hernández Castellón, 2004, Dinámica Demográfica I, Notas de 
Clase, Maestría en Demografía Social, UNAH/PLATS.

Honduras, SEDP, PNUD, PLATS/UNAH, El Occidente de Honduras, tierra de carencias y esperanzas: tendencias de desarrollo e impactos de los procesos de intervención pública en los últimos 50 años, 1era ed, Tegucigalpa (Alin Editora), diciembre de 2005, $215 \mathrm{p}$.

INE, 2001 - 2015 Proyecciones de población de Honduras.

Issler, Juan R, Revista de Posgrado de la Cátedra VIa Medicina № 107 - agosto/2001, p. 11-23, Embarazo en la adolescencia.

OPS, 1992, Silver, Tomas, y otros, Manual de medicina de la adolescencia, serie PALTEX para ejecutores de salud $\mathrm{N}^{\circ} 20$, Washington D. C., E.U.A

OPS, 1995 Maddaleno, Matilde, y otros, La salud adolescente y del joven, publicación científica 552, Washington D. C., E.U.A

Pineda, Noé, 1997, Geografía de Honduras, Editorial Guaymuras, tercera edición, Tegucigalpa, Honduras.

Population Reference Bureau, 2004, Washington, DC, EE.UU.

Programa de las Naciones Unidas para el Desarrollo, 2004, Informe sobre Desarrollo Humano Honduras 2003.

Rivas, Ramón, 2000, Pueblos indígenas y garífunas de Honduras, una caracterización, editorial Guaymuras, Tegucigalpa, Honduras.
Sánchez Lam, 1998, Cecilia Lizeth, Los círculos viciosos: La maternidad en la adolescencia, CSUCA/ Fundación Ford, 1992, citado por, Secretaría de Salud Pública, Departamento de Salud MaternoInfantil, Unidad de Atención integral al escolar y al adolescente, Bases programáticas Programa de atención integral a la adolescencia, Tegucigalpa, Honduras.

Secretaría de Salud Pública, 1998, Departamento de Salud Materno-Infantil, Unidad de Atención integral al escolar y al adolescente, Bases programáticas Programa de atención integral a la adolescencia, Tegucigalpa, Honduras.

Secretaria de Salud, 1997-2001, Departamento de Estadística, Salud en Cifras.

UNFPA, 1994, Programa de Acción, Población y Desarrollo: Un compromiso universal, Conferencia Internacional de Población y Desarrollo, El Cairo, Egipto.

UNFPA, 2003, Estado de la población mundial, New York, NY 10017, Estados Unidos de América.

UNFPA, 2004, Estado de la población de Honduras, Folleto, Casa de las Naciones Unidas, Colonia Palmira, Tegucigalpa, Honduras.

UNFPA, 2004, Informe de la Conferencia Internacional sobre Población y Desarrollo, El Cairo, Egipto, septiembre de 1994, El consenso de El Cairo, Diez años después, Tegucigalpa, Honduras. 